\title{
Performance prediction methods of HF radio systems
}

\author{
Rudi Hanbaba \\ France Telecom, CNET, Lannion, France
}

\begin{abstract}
A survey of the historical development of methods for predicting the performance of ionospheric HF radio systems is presented, with special emphasis on modelling. The models considered are ionospheric characteristics and electron-density profile models, a propagation model, transmission loss and gain factors models, characteristics of radio noise models and a reliability model.
\end{abstract}

Key words: modelling-propagation-prediction procedures

\section{Introduction}

The historical development of ionospheric prediction methods is reviewed. In order to provide accurate predictions, models are needed. The models considered are ionospheric characteristics and electron-density profile models, a propagation model, transmission loss and gain factor models, characteristics of radio noise models and a reliability model. Several approaches to obtain this are summarized. A survey of methods for predicting the performance of HF radio systems is presented. HF is here taken as the frequency band 1.6-30 MHz. A distinction is made between long-term predictions and short-term predictions. Finally, this paper introduces the areas where further work is required.

Long-term predictions are typically established for specified solar activity levels and

Mailing address: Dr. Rudi Hanbaba, France Telecom, CNET, Centre Lannion B, 2 Avenue Pierre Marzin, 22307 Lannion Cedex, France; e-mail: rudi-hanbaba@cnet. france telecom.fr months. The methods are based on climatological models of the ionospheric behaviour developed from a long series of past measurements. The prediction itself is based on the prediction of the solar activity level. The term «retrospective» is sometimes utilised for the methods to describe representative monthly median ionospheric maps.

Long-term predictions are needed for radio system design and testing, circuit planning, frequency management and service planning. Typical and extreme estimates of propagation conditions are required for radio system design and testing. For circuit planning, the prediction has an important role in providing information on the choice of transmitter location, frequency range, transmitter power, modulation and the selection of suitable antennas. Present techniques for frequency management are largely based on HF long-term predictions. It should be noted that there are relatively few studies on optimising service planning. There is also an important role for improved prediction techniques to exploit the potential of the HF spectrum to the best advantage.

Short-term predictions are relevant to time scales from minutes to days. Even under quiet conditions, the ionosphere exhibits wide day- 
to-day variations. The need for frequency management as an aid to improve radio-circuit operations has been pointed out by King and Slater (1973) and the implications of the daily variations on HF communications circuits has been analysed by Rush et al. (1974). Usually the term forecast is adopted for the practical schemes which are based on solar-terrestrial relations. In the limit of zero lead-time, the forecast becomes a real-time assessment of the ionosphere or a Real-Time Channel Evaluation (RTCE) for HF communications. The term «now-casting» is often used to describe an observation-intensive approach at very-short term (up to one hour) ionospheric forecasting.

During the last decades research efforts were first devoted to long-term predictions, then to short-term predictions. In recent years, a need appears for ionospheric mapping for a fixed epoch and a single day (instantaneous maps) for remote sensing systems (especially for over-the-horizon radars) and single-station target location systems (Bradley, 1991a,b). They also produce a wealth of information for retrospective investigations, for example to explain the reasons for communication break. Figure 1 shows the relations between the various time scales.

Prediction techniques consist of four main stages. Firstly, it is essential to predict the state of a set of selected ionospheric characteristics and to yield an electron-density height profile along the propagation path between the transmitter and the receiver. Secondly, the ray paths of all probable propagation modes must be determined. Then, it is necessary to evaluate the received sky-wave field strength (or the available receiver power) and the signal-to-noise ratio by summing the received powers from the separate ray paths. This stage includes the determination of the Maximum Usable Frequency (MUF), which is the highest frequency that would permit an acceptable performance of a radio circuit at a given time under specified working conditions, and the Lowest Usable Frequency (LUF), which is the lowest frequency that would permit an acceptable performance of a radio circuit at a given time under specified working conditions. Finally, the variability parameters of the ionosphere, which oc- curs within the hour and day-to-day within a month, are evaluated to give the probability of achieving an acceptable degree of service.

\section{Models}

The accuracy associated with any performance prediction method is critically dependant upon the ability to predict reliable models. It is not surprising that most international efforts have been devoted to modelling. Models typically require as inputs terminal locations, certain equipment information (i.e. transmitter power, transmitting and receiving-antenna gains or configuration) and terrain and sitting information, month or day of year and an index used to characterize the state of the ionosphere. In addition, certain other system information and an interference model are necessary. Only a brief review can be given in this paper but a complete reference list is provided for the interested reader. Formulae are not provided as they serve only the expert reader. These formulae are to be found in the original papers.

\subsection{Indices for ionospheric predictions}

The notion of indices for prediction is based on the assumption that the variations of the important characteristics of the ionosphere are well correlated with certain quantities associated with changes in solar and geomagnetic activity. As the state of the monthly median ionosphere depends almost exclusively on solar activity, any ionospheric prediction will be based on predictions of solar activity. Two types of indices are suitable: solar indices and ionospheric indices. Solar indices are measurable quantities of the solar activity or of a specified solar radiation. Ionospheric indices are the quantification of the global change in ionospheric characteristics at selected long-established ionospheric observing stations. It is to be noted that the correlation between these indices and the ionospheric characteristics are only evidence of associated phenomena. The 12-month running mean sunspot number $R_{12}$ has been generally adopted as the index to be used for all 


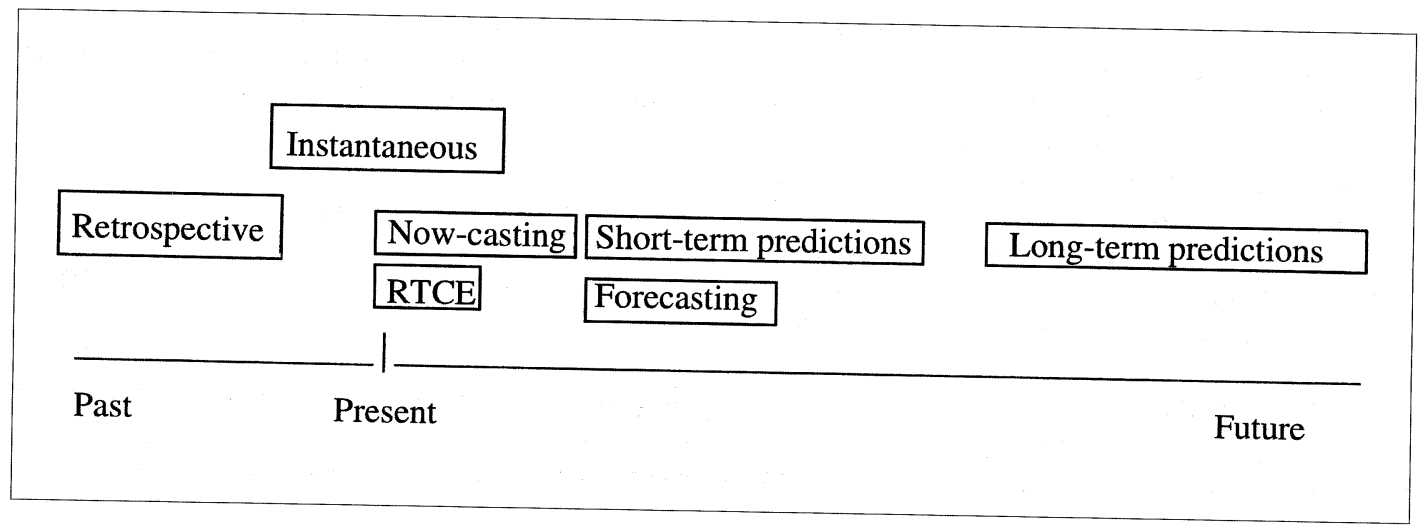

Fig. 1. Various time scales in predictions.

long-term ionospheric predictions. Nevertheless the solar noise flux about $10 \mathrm{~cm}$ wavelength made in Canada should be regarded as the reference index for dates up to one month. The index $T$ which was developed in Australia (IPSD, 1968) especially for use with the Australian ionospheric maps has been adopted on various other occasions. A survey of different available indices for long term ionospheric predictions has been provided by the International Telecommunication Union Radio- communication Sector (ITU-R, 1995a). Recommended choice of indices to be used in different scenarios is given. Investigation is being done of the merit of an effective sunspot number $\operatorname{SSN}_{e}$ (Secan and Wilkinson, 1997) and an improved new ionospheric index $M F_{2}$ (Mikhailov and Mikhailov, 1995). This $M F_{2}$ index provides the best critical frequency of the $F_{2}$-layer versus solar activity regression compared to the usually adopted indices. However it is recognised that no index is perfect but at the present time understanding of solar-terrestrial relationships is not complete, although work is advancing.

\subsection{Ionospheric characteristics}

The regular observations from the groundbased ionosondes network provided the bases for the development of numerical representations of an appropriate choice of ionospheric characteristics. For the prediction of the monthly median value of the $E$-layer critical frequency $\left(f_{0} E\right)$ and the $F_{1}$-layer critical frequency $\left(f_{0} F_{1}\right)$, empirical formulae in terms of solar-zenith angle are usually adopted. For the other ionospheric characteristics a numerical mapping technique based on orthogonal functions is generally applied.

\subsubsection{Global mapping}

The ITU-R provides recommended expressions for the prediction of ionospheric characteristics. The formulations yield values for any location, month and time-of-day for different solar epochs. Details are given in ITU-R (1997a). Computer programs associated with the prediction procedures are available from the ITU (ITU-BR, 1997).

The representation of $f_{0} E$ currently recommended by the ITU-R was given by Muggleton (1975). The method is based on all published data over the years 1944-1973 from 55 ionospheric stations. The formulae are very accurate except around sunrise and sunset where the solar zenith angles are large: tests of the accuracy give a median standard deviation of $0.11 \mathrm{MHz}$. It is to be noted that the computer program of ITU-BR contains revisions of the original equations derived by Muggleton. 
The derived expressions for predicting $f_{0} F_{1}$, currently recommended by the ITU-R, are based on data recorded from 1954 to 1966 at 39 ionospheric stations located in both hemispheres (Ducharme et al., 1973). Improvements of the $F_{1}$-layer model should be shortly finalized, especially regarding the critical frequency (Zolesi and Mosert de Gonzalez, 1995) and the probability of the occurrence of the $F_{1}$ ledge (Scotto et al., 1997).

Models of the critical frequency of the $F_{2}$-layer $\left(f_{0} F_{2}\right)$ and $M(3000) F_{2}$, a factor which, when multiplied by $f_{0} F_{2}$, gives the Maximum Usable Frequency (MUF) were developed by Jones and Gallet (1965), Jones et al. (1969) and Jones and Obitts (1970) and are also available in the form of a set of numerical coefficients for each month of the year and for reference levels of low and high solar activity (ITU-BR, 1997). The numerical representation was made in universal time, rather than in local time as it was usually made at the time of the original papers, and a modified magnetic dip was adopted as the main latitude coordinate instead of geographic latitude. The general form of the numerical mapping function is the Fourier time series. Values of $f_{0} F_{2}$ and $M(3000) F_{2}$ for any solar activity level are calculated by linear interpolation or extrapolation deduced from the coefficients for the two reference levels of solar activity. In the case of $f_{0} F_{2}$, a second set of coefficients (Jones and Obitts, 1970), based on a parabolic dependence on solar activity index, produces $f_{0} F_{2}$ values for any day of the year and for any solar activity. The first coefficient set was adopted by the CCIR in 1966, previously named the «CCIR coefficient» set, and up to now recommended by the ITU-R. Data for five years, 1954, 1955, 1956, 1957 and 1958, were analysed. The use of data from 1964, to supplement the 1954 data, was necessary to fill some large gaps for mapping most of the southern hemisphere. With the irregular distribution of ionosondes and the absence of measurements over the oceans, there are a number of known major deficiencies. Using further ionosonde data sets, new $f_{0} F_{2}$ maps have been produced. At once, a different set of coefficients was developed using observed values of $f_{0} F_{2}$ and theoretically generated values in order to improve the representation of $f_{0} F_{2}$ over the oceans and other regions where no ionosondes have existed (Rush et al., 1984). Then, using more recent data and theoretically generated values over the oceans, a new set of coefficients, named the «URSI coefficient» set, was generated (Fox and Mc Namara, 1988; Rush et al., 1989). No updates of the $M(3000) F_{2}$ maps have been completed.

A set of numerical coefficients defining the diurnal, geographical and seasonal variations of the medians and upper and lower deciles of $f_{0} E_{s}$, critical frequency of the sporadic- $E$ layer, for a year of minimum solar activity and one of maximum solar activity, and a set of numerical coefficients defining the variations of the medians and upper and lower deciles of the $f_{0} E_{s}$ (blanketing sporadic- $E$ ) for a year of minimum solar activity were produced by Leftin et al. (1968) and Leftin and Ostrow (1969) respectively. The mapping procedure of Jones and Gallet (1965) was adopted. Unfortunately, the coefficients are based only on the data from a few stations and many deficiencies appear on the global-scale representation by the non-existence of a truly global set at the time when the coefficients were assembled. Using a different approach, a prediction method was developed in the former U.S.S.R. which provides the probability of $E_{\mathrm{s}}$ reflection at a given frequency (Chernishyev, 1968) and maps showing the percentage of time for which $f_{0} E_{s}$ exceeds $7 \mathrm{MHz}$ were also produced by Smith $(1976,1978)$.

The percentage occurrence of spread- $F$ was determined from the ionospheric data from the network of vertical-incidence ionosonde stations for a year of high solar activity and for a year of low solar activity (Davies, 1972). The mapping technique of Jones et al. (1969) was used.

Numerical maps have been also generated using the same technique for years of maximum and minimum of solar activity of $h^{\prime} F$, which is the minimum observed virtual height of reflection of vertical incidence signals from the $F$ region (generally from the $F_{2}$-layer at night and from the $F_{1}$-layer in the daytime), and of $h^{\prime} F, F_{2}$, which is the minimum observed virtual height of reflection of vertical incidence signals from the $F_{2}$-layer both at night and in 
the daytime (Leftin et al., 1969). The mapping technique of Jones et al. (1969) was also used.

\subsubsection{Regional ionospheric mapping}

Section 2.2.1. notes that major deficiencies on the global-scale representation appear with the irregular distribution of the verticalincidence ionosonde stations and that the global maps in current international use are based on measurements taken three decades ago. However, in some areas, large data sets are now available. Specifically, Europe has a very large data set of measurements and this offers the possibility to develop improved models for the European region.

The procedure which has been established in the framework of COST (European Cooperation in the Field of Scientific Research) Action 238 (PRIME, Prediction and Retrospective Ionospheric Modelling over Europe), for the geographical area between latitudes $35-55^{\circ} \mathrm{N}$ and longitudes $10^{\circ} \mathrm{W}-30^{\circ} \mathrm{E}$, are significantly better than those derived from existing global methods (COST, 1995). An important aspect of the work was to provide an interface to global maps and models outside the European area. This was achieved by means of a «buffer zone» for a smooth transition in this region. Principal features are embodied in a final computer program with a range of optional outputs for microcomputer evaluation. One of the objectives of a follow-on Action 251 (Improved Quality of Service in Ionospheric Telecommunication Systems Planning and Operation) is to further refine these models and to widen their geographical area of applicability to $70^{\circ} \mathrm{N}$ northwards and $60^{\circ} \mathrm{E}$ eastwards. A review of progress in regional mapping has been provided by Zolesi and Cander (1996a), with the emphasis on work in the frame of COST 238 and 251 projects.

In this frame, several regional models have been developed to provide improved long-term maps of $f_{0} F_{2}$ and $M(3000) F_{2}$ within the European area. The potential of two of these techniques, based on the simplified ionospheric regional model and on adjusted spherical cap harmonic analysis procedures, were adopted and applied by Zolesi et al. (1996) to different mid-latitude areas such as Northeast America, Northeast Asia, Southeast America and Southeast Australia. Notwithstanding the simple model formulation and the reduced number of numerical coefficients involved, a good agreement was found between the modelled and observed monthly medians for the selected ionospheric parameters coming from a sparse network of stations operating within the above regions.

A new monthly median $f_{0} F_{2}$ and $M(3000) F_{2}$ model, $M Q M F_{2}$, based on the multiquadric method of spatial interpolation and the new effective ionospheric index $M F_{2}$ was derived for the European region (Mikhailov et al., 1996). A non-linear dependence of $f_{0} F_{2}$ and $M(3000) F_{2}$ on solar activity level, expressed by $M F_{2}$ index, was adopted to generate local models for each ionosonde station. Outside the COST 251 area the model smoothly interfaces to the global ITU-R model. The multiquadric method allows a surface to be drawn strictly over a given set of points unlike other currently used mapping methods. The $M Q M F_{2}$ method provides better accuracy than the ITU-R model in retrospective mode over Europe.

Other regional models for $f_{0} F_{2}$ and $M(3000) F_{2}$ have been developed for different areas of the world. For example, the Chinese Reference Ionosphere (CRI) model was developed for use in the Chinese subcontinent (Jiao and $\mathrm{Wu}$, 1996). A prediction method of the median $f_{b} E_{s}$ for temperate latitudes was also developed by Giraldez (1980).

\subsubsection{Instantaneous ionospheric mapping}

Instantaneous mapping is defined as the technique that is applied when simultaneously measured or forecast values of ionospheric characteristics at limited numbers of locations are utilised for map generation appropriate to a single moment of time. Generally the number of measurement locations is insufficient for the production of fully accurate maps, even over a restricted geographical region, and artificial screen-point values must be used to constrain 
the mapping contours in remote areas without no-physical gradients of electron concentration (Stanislawska et al., 1996). The methods comprise choosing the form of the smoothing functions between the measurements and of adopting screen-point values in regions where there are no measurements. Reviews of instantaneous ionospheric mapping methods were made by Bradley (1993a,b, 1996) who considers three classes of approach to mapping.

Harmonic fit over a geographic grid - Various functional representations are possible, for example, Adjusted Spherical Harmonic Analysis (De Franceschi and De Santis, 1995), Empirical Orthogonal Functions (Singer and Dvinskikh, 1991), multiquadric method with additional screen-points generated by single-stations models and external zone points generated by global model (Mikhailov et al., 1995).

Contouring - The techniques involve the generation of a uniform latitude-longitude grid of values and interpolation among these with gridding achieved by Kriging (Samardjiev et al., 1993; Bradley et al., 1995; Stanislawska et al., 1996), minimum curvature or inversedistance procedures.

Physical models - Parameterised versions of theoretical models, where the theoretical model is parameterised in terms of solar-terrestrial factors, have been developed on a global scale (Tascione et al., 1988; Daniell et al., 1993) or for restricted areas (Anderson et al., 1987, 1989).

Examples of available methods that should be utilised for instantaneous regional mapping are listed in table I. There are currently no available methods of producing global instantaneous maps.

\subsection{Electron-density height profile}

The availability of a model of the electron-density height profile is fundamental for supplying HF propagation predictions. The pro- file models that are currently in use can be divided into three types: theoretical, parameterised and empirical models. Different approaches to achieving this have been reviewed by Cander et al. (1996) and Radicella (1996).

Theoretical models are based on the solution of the equations controlling the ionospheric plasma. Only under very approximated assumption is this analytical, and even so, the boundary conditions are extremely complex. However, important progress has recently been made and the finest models reproduce the main climatic ionospheric variations. Nevertheless, because of their complexity, theoretical models are not suitable for operational modelling on HF radio propagation but are appropriate for specific geophysical studies and must be helpful to improve the knowledge of the complex physical processes existing in the ionosphere. In particular, they supply useful figures for generating and testing new models. Furthermore, some inputs parameters of the theoretical models are not accessible everywhere and the accuracy of these inputs limits the overall accuracy of the model.

Parameterised models (see section 2.2.3.) are primarily suitable for instantaneous ionospheric mapping.

Empirical models are based on the ionospheric characteristics obtained from the network of vertical-incidence ionosonde stations. They are best approximations for supplying HF propagation predictions. In order to attain a whole electron-density height profile, the ionospheric characteristics models must be coupled with a presumed distribution of the electron-density. Several empirical models are listed in table II. The best known and widely applied empirical model is the International Reference Ionosphere (IRI), (Bilitza, 1990) produced by a joint COSPAR/URSI Working Group. This model is given in terms of LAY functions (Bossy, 1987) to provide a smooth height variation of electron density and gradient, therefore making the model appropriate for ray-tracing applications. Investigation has continued to improve the IRI (Bilitza et al., 1993; Bilitza, 1997) and different refined versions of this model have been released. Information on 
Table I. Available instantaneous regional mapping methods.

\begin{tabular}{|c|c|c|}
\hline Model & References & General characteristics \\
\hline SLIM & Anderson et al. (1987) & $\begin{array}{l}\text { Semi-empirical Low-latitude Ionospheric } \\
\text { parameterised Model }\end{array}$ \\
\hline ICED & Tascione et al. (1988) & $\begin{array}{l}\text { Ionospheric Conductivity and Electron Den- } \\
\text { sity parameterised Model }\end{array}$ \\
\hline FAIM & Anderson et al. (1989) & $\begin{array}{l}\text { Fully Analytical low- and middle-latitude } \\
\text { Ionospheric parameterised Model }\end{array}$ \\
\hline PRISM & Daniell et al. (1993) & $\begin{array}{l}\text { Parameterised Real Time Ionospheric Speci- } \\
\text { fication Model }\end{array}$ \\
\hline KIM & Samardjiev et al. (1993) & Kriging approach \\
\hline KIM2 & Bradley et al. (1995) & Kriging approach with screen-points \\
\hline IMASHA & De Franceschi and De Santis (1995) & Adjusted Spherical Harmonic Analysis \\
\hline MQMF2-IM & Mikhailov et al. (1995) & $\begin{array}{l}\text { Multiquadric method with ionospheric index } \\
M F_{2} \text { and with additional screen-point values }\end{array}$ \\
\hline $\mathrm{K} 2$ & Stanislawska et al. (1996) & Kriging approach \\
\hline
\end{tabular}

Table II. Empirical electron-density height mapping methods.

\begin{tabular}{|c|c|c|}
\hline Model & References & General characteristics \\
\hline Bradley and Dudeney & Bradley and Dudeney (1973) & $\begin{array}{l}\text { Parabolic and linear segments, no } D \text { and } F_{1} \text { re- } \\
\text { gions, no } E-F \text { valley, UIT-R peak parameters }\end{array}$ \\
\hline Chiu model & Chiu (1975) & $\begin{array}{l}\text { Three Chapman functions for the } E-, F_{1} \text { and } \\
F_{2} \text {-layer, phenomenological description of peak } \\
\text { layers parameters }\end{array}$ \\
\hline Bent & Bent et al. (1976) & $\begin{array}{l}\text { Three exponential topside segment, bottomside } \\
\text { bi-parabolic }\end{array}$ \\
\hline Dudeney & Dudeney (1978) & $\begin{array}{l}\text { Trigonometric-function segments, no } D \text { region, } \\
\text { no } E-F \text { valley, UIT-R peak parameters }\end{array}$ \\
\hline RADARC & Thomason et al. (1979) & $\begin{array}{l}\text { Parabolic } E-\text { and } F_{2} \text {-layers, linear or parabolic } \\
F_{1} \text {-layer, } E-F \text { valley, ITS peak parameters }\end{array}$ \\
\hline IONCAP & Teters et al. (1983) & $\begin{array}{l}\text { Parabolic and linear segments, exponential de- } \\
\text { crease below } E \text { region, } E-F \text { valley, UIT-R peak } \\
\text { parameters }\end{array}$ \\
\hline IRI & Bilitza (1990) & $\begin{array}{l}\text { Special functions, called LAY-functions, for } D \text { - } \\
\text { and } E \text {-layer, } E-F \text { valley, } F_{1}-\text { and } F_{2} \text {-layer, modi- } \\
\text { fied Bent model for topside ionosphere }\end{array}$ \\
\hline RAL multi-quasiparabolic & Dick and Bradley (1992) & $\begin{array}{l}\text { Seven segment quasi-parabolic, continuity of } \\
\text { profile and gradient, UIT-R peak parameters }\end{array}$ \\
\hline DGR & Radicella and Zhang (1995) & $\begin{array}{l}\text { Epstein layers formulation, characteristic points } \\
\text { of empirical expressions }\end{array}$ \\
\hline AVR & Huang and Reinisch (1996) & $\begin{array}{l}\text { Average representation of boundary values and } \\
\text { coefficients from digisonde ionograms }\end{array}$ \\
\hline
\end{tabular}


the current activity of electron density height profile shape below $F_{2}$ peak-density is given in the Proceedings of the IRI Task Force Activity 1995 (Radicella, 1995). The simple empirical model produced by Bradley and Dudeney (1973) was recommended by the ITU-R. It consists of a parabolic $E$-layer, a linear increase in electron-concentration with height in the $F_{1}$ region and a parabolic $F_{2}$-layer. Difficulties in ray-tracing application appear with discontinuities of profile and gradient in this model. Recommended procedures for ray-path predictions in ITU-R (1997a) use now the RAL multiquasiparabolic model ionosphere (Dick and Bradley, 1992) which provides continuity of profile and gradient.

The possibility of interfacing region and global electron density height profile models over a buffer zone was analysed by Zolesi and Cander (1996b).

\subsection{Transmission loss and gain factors}

The choice of the optimum working frequency depends above all on the available receiver power. This parameter is directly related to the attenuation along the link and the performance of the equipment used (transmitter power, transmitting and receiving-antenna gains). The available receiver power is estimated in terms of a number of factors which are given by empirical equations or deduced from theory.

\subsubsection{Spatial attenuation}

Spatial attenuation is due to the fact that transmitted energy diverges from the antenna (propagation in free space), but a certain convergence is produced in the ionosphere, which in this way acts as a concave mirror. It is suitable to consider spatial attenuation as consisting of two components: an equivalent freespace attenuation and a focus gain. Focusing is important only on low elevation paths (about 10 and $3 \mathrm{~dB}$ at 1 and 8 degrees elevation angle respectively but only about $1 \mathrm{~dB}$ at 60 degrees).
Current empirical equations are based on raytracing calculations through a representative set of ionospheric models.

\subsubsection{Ionospheric absorption}

Ionospheric absorption is usually the major loss after spatial attenuation in HF propagation. The term non-deviative absorption is used to denote the loss in the $D$ - and $E$-regions when the refractive index is approximately equal unity and deviative absorption in other cases. At high latitudes there is an additional nondeviative absorption associated with the arrival of energetic electrons and solar protons from the magnetosphere under disturbed conditions.

\subsubsection{Non-deviative and deviative absorption}

The estimation of non-deviative and deviative absorption is derived from vertical-incidence absorption measurements and ray-tracing calculations. The absorption is approximately proportional to the number of collisions per second and inversely proportional to the square of the frequency, except for the lowest part of the HF band. The classical model is that described by George and Bradley (1974). In this approach, the absorption is given in terms of the solar zenithal angle, the season, the location, the frequency, the electron gyrofrequency, the number of ionospheric reflections, the angle of elevation of the ray at the ground and the solar activity. Non-deviative absorption increases rapidly with increase in solar zenith angle and decrease of frequency (for a path length of $5000 \mathrm{~km}$ and medium solar activity, about $5 \mathrm{~dB}$ during midnight at frequencies near the MUF and about 50 $\mathrm{dB}$ at noon at frequencies half the MUF). Deviative absorption is usually less than $2 \mathrm{~dB}$ and introduced as a correction factor in the $a b-$ sorption equation.

\subsubsection{Auroral absorption}

If trajectories penetrate zones of high latitude, absorption may be considerably greater 
because of the increased electron concentration at low altitudes. Although the wide day-to-day auroral absorption variability, it is usually accepted that the monthly median auroral absorption can be represented numerically. The available empirical models make use of riometer data. Among the different models, a preference should be given to the model proposed by Foppiano (1985). This model makes use of riometer data from 27 stations mainly in the Northern hemisphere. The empirical relations are expressed in terms of corrected geomagnetic latitude, corrected geomagnetic longitude and corrected geomagnetic local time.

\subsubsection{Sporadic- $E$ obscuration and reflection losses}

The «expression sporadic- $E$ obscuration losses» is adopted to define the losses by scattering from sporadic- $E$ associated with passages through this region. Obscuration losses are introduced using empirical relations derived from HF signal-strength measurements using a procedure established by Sinno et al. (1976). Obscuration losses are expressed in terms of frequency, $f_{0} E_{s}$ and zenith angle of the oblique ray at a height of $110 \mathrm{~km}$.

A technique for estimating sporadic- $E$ reflection losses as a function of frequency, midpath value of $f_{0} E_{\mathrm{s}}$ and distance was developed by Miya et al. (1978). This technique was modified by Teters et al. (1983). Although the method was based on signal-strength measurements essentially at VHF for middle-latitude paths, this is taken as applying for all latitudes. It should be noted that sporadic- $E$ modes are taken into account in almost all procedures only for frequencies above the monthly median MUF.

\subsubsection{Polarization-coupling loss}

An upgoing wave incident on the ionosphere is divided into an Ordinary $(\mathrm{O})$ and an Extraordinary $(\mathrm{X})$ wave. These two waves may be regarded as propagating separately in the iono- sphere with more or less different ray paths and different absorptions. The fractions of power coupled to the $O$ and $X$ waves and, as a consequence, the fractions of power coupled to the receiving antenna depend on the polarization of the wave after the exit from the ionosphere. Results have been presented by Bradley (1968). Polarization-coupling loss is usually less than $5 \mathrm{~dB}$ but in some circumstances it is greater than $20 \mathrm{~dB}$. Although this shows that it is important to include a full computation of polarization-coupling loss in a prediction procedure, this is generally not expressly calculated.

\subsubsection{Multi-hop ground-reflection loss}

Multi-hop ground-reflection losses are calculated in terms of Fresnel-reflection coefficients for a circularly-downcoming wave. The Fresnel coefficients can be evaluated as a function of the elevation angle of the downcoming wave, the frequency, the ground conductivity and the relative dielectric constant. The ground electrical characteristics can be derived from a numerical map of land-sea and land-ice boundaries. The map adopted in CCIR (1980) also gives a gradual transition between the limiting values near the land-sea and ice-sea boundaries. These calculations are lengthy and are not introduced in most of the prediction procedures. A constant loss of $2 \mathrm{~dB}$ per hop irrespective of ground characteristics, frequency and angle is generally adopted.

\subsubsection{Loss associated with propagation at frequencies above the MUF}

Reception of the signal is often achieved at frequencies above the predicted MUF. Propagation mechanisms which may give rise to propagation at frequencies above the MUF are as follows : ionospheric roughness, ground back- and side-scatter, higher order mode back-scatter, ducted modes, chordal hop propagation, direct ionospheric scatter, sporadic-E propagation, auroral scatter and meteor scatter. The different mechanisms are described in ITU-R (1997b). 
The various formulae which have proposed for above the MUF loss are described by Hagn et al. (1994). Two simple empirical expressions, respectively for $E$ and $F$ modes, are adopted in ITU-R (1995b) to give a smooth decrease of field strength with increase in frequency. Above the MUF, losses increase rapidly with increase in frequency (about $30 \mathrm{~dB}$ at frequencies 1.5 time the MUF). Work is in progress within the ITU-R to devise a more accurate method.

It should be noted that the estimation of the above the MUF loss is of great interest for the prediction of signal strength of interfering signals which may be received at frequencies above the MUF. Prediction of the desired signal at frequencies above the MUF is less useful because the propagation mechanisms involved give rise to a multitude of time delays.

\subsubsection{Transmitting and receiving-antenna gains}

The transmitting and receiving-antenna gains along the ray directions are required to evaluate the available receiver power. Generally the most reliable estimates of gains are obtained from measurements. Antenna pattern is then introduced as a matrix of numbers. Unfortunately, such information is habitually not available and use must be made of theoretical values. For many applications the procedure developed by Haydon et al. (1976) should be used. The equations are pertinent for various basic types of antenna situated over horizontal uniformly plane ground of finite conductivity. For broadcasting planning, the information in ITU-R (1995c) should be used.

\subsubsection{Day-to-day variations}

The loss terms presented in the previous sections give estimates of the monthly median value of the overall transmission loss. The day-to-day variations in signal strength are usually determined by adopting tables of transmission-loss variability parameters $T_{u}$ and $T_{l}$, separately for transmission ranges less than or equal to $2500 \mathrm{~km}$ and greater than $2500 \mathrm{~km}$, as a function of season, midpath local mean time and midpath geomagnetic latitude (Barghausen et al., 1969). $T_{u}$ is the deviation exceeded from the monthly median transmission loss for $10 \%$ of the time and $T_{l}$ is the transmission loss exceeded from the monthly median transmission loss for $90 \%$ of the time.

\subsection{Characteristics of radio noise}

For the estimation of the performance of HF radio systems, it is insufficient to consider the signal level alone. The characteristics of radio noise in the bandwidth of the receiving equipment and the level of unwanted interfering signals at the receiver are major factors limiting performance.

A requested signal-to-noise protection ratio (or signal-to-interference) value is needed to run a performance prediction computer program. ITU-R Recommendations 240 (ITU-R, 1994a) and 339 (ITU-R, 1994b) provide signal-to-noise ratios and signal-to-interference protection ratios required for various classes of emission in the fixed service and ITU-R Recommendation 560 (ITU-R, 1997c) provides information on radio frequency protection ratios required in the broadcasting service respectively.

Noise can be divided into two types: noise internal to the receiving system and noise external to the receiving system. Internal noise has the characteristics of thermal noise. Only external noise is examined in this paper.

The external noise level consists of the combined noise from three main sources.

Atmospheric noise - The source of atmospheric radio noise is lightening discharges which arise during thunderstorms. The noise is propagated from all locations on the Earth to the receiving antenna. An atmospheric noise model is given in ITU-R Recommendation 372 (ITU-R, 1994c) as a function of geographic location and season within 3-h time blocks. This model is adopted universally.

Galactic noise - Galactic noise is due to extra-terrestrial sources. A median noise model is 
given in ITU-R Recommendation 372 as a function of frequency.

Man-made noise - Man-made noise is the consequence of human activity (radiation from electrical equipment, power transmission lines, ....) in the vicinity of the receiver. A man-made noise model is given in ITU-R Recommendation 372 as a function of frequency for four environmental categories (business, residential, rural and quiet rural).

Atmospheric noise usually predominates. However for a number of environments (industrial or business areas) in which atmospheric noise is at a low level, man-made noise may dominate the overall radio noise.

The unwanted signals from known transmitters may be estimated in the same way as the wanted signal. Interference is often greater at night due to decreased absorption. The effect of unknown transmitters is not easily quantified. Only models for a limited number of locations have been established.

\subsection{Propagation model}

In the frequency range concerned, the Earth's surface is generally a good reflector, a ray path between two terminals near the Earth's surface may incorporate several successive reflections, alternately from the ionosphere and the ground. There may even be successive reflections between two different ionospheric layers. The sky-wave paths considered are ray paths via reflections from the regular $E$-layer, the sporadic $E$-layer, the $F$-layer and mixed modes. The maximum distance reached in a single hop is limited for purely refraction reasons, this distance seldom exceeds $2300 \mathrm{~km}$ for a sporadic $E$-layer mode, $2500 \mathrm{~km}$ for a regular $E$-layer mode and $3500 \mathrm{~km}$ for an $F_{2}$-layer mode. The $F_{1}$-layer modes are important only for distances in the $2000-3400 \mathrm{~km}$ range during the summer months. The mixed modes are considered only for long distance links (usually longer than $2500 \mathrm{~km}$ ) and consist of one or two
$E$-layers, or one sporadic $E$-layer, and one or two $F$-layer reflections. However for operational reasons (i.e. antennas beamwidths), ray paths must have elevation angles exceeding a minimum specified value. Consequently of, the maximum distance that can be reached in a single hop is lower than the above limits. It should be noted that sporadic E-layer modes are usually not introduced to calculate the operational MUF but are only considered to calculate signal-strength.

A knowledge of the MUF is needed to calculate the mode availability. The path MUF is taken as the highest MUF of the different modes. Firstly, it is necessary to define the position of the points along the propagation path at which the ionospheric parameters will be predicted (the so-called «control-point procedure»). MUFs may be evaluated by raytracing procedures. Ray computations should be made for series of increasing frequencies until no propagation path to the desired transmission distance is feasible. Nevertheless, for operational reasons, a simpler approach based on empirical formulae is adopted most of the time. For example, MUFs are the product of critical frequency and a «distance factor» obtained from empirical equations as a function of path length and reflecting layer height in the procedure recommended by the ITU-R (1997d).

The probability that a ray path which has been obtained using monthly median values of the ionospheric characteristics will exist on a given day of the month can be evaluated in terms of the statistics of the day-to-day variations of the MUF. It is generally assumed that MUF variations follow a $\chi^{2}$-distribution. The day-to-day variations of MUF of $F$-modes are usually determined by adopting tables of variability parameters $F_{u}$ and $F_{l}$ for different ranges of $R_{12}$, as a function of season, midpath local mean time and midpath geographic latitude (Barghausen et al., 1969) where $F_{u}$ is the ratio of the upper decile to the median MUF and $F_{l}$ is the ratio of the lower decile to the median MUF. The $f_{0} E$ is relatively constant from day-to-day and fixed values of $F_{u}=1.05$ and $F_{l}=0.95$ are taken as applying to the MUF for $E$-modes. 


\subsection{Reliability}

The main parameters given by most HF prediction methods in the 1980s were the MUF and the field strength. However the practical requirements of radiocommunication necessitate information, not only on the MUF and the median value of the received signal intensity, but also on the variations of the amplitude and dispersion of the desired signals and of the background noise and interference.

Two parameters of an HF radio system which may be used to quantify the performance are the predicted reliability and the predicted compatibility. Reliability is defined as the probability that a specified performance will be achieved by the system. Compatibility is a measure of the degradation a circuit, or a service, will suffer in the presence of interference. In the case of a single point-to-point circuit, circuit compatibility is defined by the percentage of time during which a specified criterion of service quality is achieved at the receiver location in the presence of interference relative to the value that would be obtained if only noise were present. The above terms are preceded by the word «basic» when the background is noise alone and by «overall» when the background is noise and interference. For broadcasting applications the minimum field strength is adopted as the specified performance. For many other applications it is convenient to adopt a given value of signal-to-background ratio as the specified performance. Recommendation ITU-R P.842 (ITU, 1994d) defines various classes of reliability and compatibility which are convenient to point-to-point circuit, area coverage from one transmitter and network applications. Reliability and compatibility of HF radio systems may be estimated according to the procedures described in this Recommendation.

The evaluation of the basic circuit reliability requires the following parameters: monthly median available receiver signal power, monthly median atmospheric, man-made and galactic noise powers, upper and lower decile deviations (day-to-day and within-the-hour) from the monthly median signal and noise powers and required signal-to-noise ratio. The computation of overall circuit reliability is similar to the computation of basic circuit reliability except the received powers from the potentially interfering transmitters are summed and compared with the available signal to determine the day-to-day and the within-the-hour distribution of hourly median signal-to-interference ratios. This distribution is introduced with the hourly median signal-to-interference ratio required for the specified performance to compute the fraction of time within the month the circuit can be expected to operate successfully in the presence of interference only. This percentage is compared with the basic circuit reliability and the

Circuit parameters (locations, power, antennae, bandwidth, required signal-to-noise ratio), hour, month, solar activity index

Determine ionospheric reflection positions, Earth's magnetic field, electrical ground parameters

Compute antenna patterns

Predict values of ionospheric characteristics and model parameters

Evaluate atmospheric, man-made and galactic noise

Determine MUF

Evaluate monthly median sky-wave field strength (or available receiver power), signal-to-noise ratio, LUF

Predict signal upper and lower decile deviations (day-today and within-the-hour)

Predict signal-to-noise upper and lower decile deviations (day-to-day and within-the-hour)

Compute basic circuit reliability (BCR)

Fig. 2. Simplified schematic representation of the stages of computation of performance prediction when the background is noise. 
overall circuit reliability is the lower of these percentages. Figure 2 is a simplified schematic representation of the stages of computation of performance prediction when the background is noise alone and fig. 3 is this representation when the background is noise and interference. It should be noted that the method requires assumptions and approximations because there are no accessible data concerning the correlation among the various modes which may simultaneously exist.

\section{Performance prediction procedures}

\subsection{Early studies}

Prevailing procedures for HF performance prediction evolved progressively, starting in the 1930 s with uncoordinated studies by radio scientists and engineers in some countries. Priority was assigned to the estimation of the monthly median MUF. Work started above all during World War II in different European countries, Japan and U.S.A. with simple procedures using hand-made charts and monograms, when no computers were available.

The first network of ground-based ionosondes was established during World War II providing the basis for the production of charts and monograms for estimating the MUF. Immediately following World War II, the United States agency Central Radio Propagation Laboratory (CRPL) of the National Bureau of Standards and the French organization Service des Prévisions Ionosphériques Militaire (SPIM) were established and the first methods were developed (NBS, 1948; Laitinen and Haydon, 1950; Rawer, 1952). These procedures were arduous and time consuming.

The development of analytical methodologies began with the advent of mainframe computers. Action has been continued and, with the rapid progress of microcomputers in the first half of the $1980 \mathrm{~s}$, a number of different implementations of microcomputer methods have been produced, at the beginning by governmental organizations, then by radio amateurs and lastly by commercial organizations. Several graphic and tabular output options provided dif-
Circuit parameters (locations, power, antennae, bandwidth, required signal-to-noise and signal-to-interference ratio), hour, month, solar activity index

Determine ionospheric reflection positions, Earth's magnetic field, electrical ground parameters

Compute antenna patterns

Predict values of ionospheric characteristics and model parameters

Evaluate atmospheric, man-made and galactic noise

Determine MUF

Evaluate monthly median sky-wave field strength (or available receiver power) of wanted signals, signal-to-noise ratio, LUF

Evaluate monthly median available receiver power of interfering signals and resultant signal-to-interference ratio

Predict upper and lower decile deviations (day-to-day and within-the-hour) of wanted and interfering signals

Predict signal-to-noise upper and lower decile deviations (dayto-day and within-the-hour) of wanted and interfering signals

Evaluate reliability in the presence of interference only (without noise)

Compute basic circuit reliability (BCR)

Compute overall circuit reliability (OCR)

Fig. 3. Simplified schematic representation of the stages of computation of performance prediction when the background is noise and interference.

ferent combinations of parameters like ionospheric characteristics, antenna patterns, median and decile MUF and LUF, optimum working frequency, take-off angles, propagation modes, sky-wave field strength, available receiver power, signal-to-noise ratio or service reliability. Much attention has been devoted to 
friendly presentation. Several «standard» inputs and outputs have been widely adopted. This section reviews the steps towards improved procedures.

\subsection{Historical development of ITU methods}

There has been more than forty years of intensive efforts in the International Telecommunication Union (ITU) involving a number of countries.

In 1956 the CCIR established a Working Party to try to develop an agreed method for international use, to produce an associated computer program, to promote sky-wave field strength measurements and to generate procedures for comparing measurements and predictions. The first objective was to amalgamate the procedures developed in different countries. Four separate prediction methods were subsequently generated by the CCIR/ITU-R.

The first CCIR method «Report 252-2» was adopted in 1970 (CCIR, 1970) by mixing different aspects from various prediction methods (Barghausen et al., 1969; Beckmann, 1967; Halley, 1965; Harnischmacher, 1960; Kasantsev, 1956; Laitinen and Haydon 1950; Lucas and Haydon, 1966; Miya and Kanaya, 1955; NBS, 1948; Piggott, 1959; Rao, 1952; Rawer, 1952). It was recognised that the method was generally satisfactory but it has a number of imperfections.

The Working Party investigated potential improvements and different feasible approaches were proposed. A ray path homing procedure was applied. The George and Bradley (1974) ionospheric absorption, the Foppiano (1985) auroral absorption, horizontal and antipodal focusing, sporadic- $E$ reflection losses and above-the-MUF loss were introduced. The second CCIR method «Supplement to Report 252-2» was then issued in 1980 (CCIR, 1980). The concept of this method, which incorporated more advanced ionospheric and propagation model, is more refined. However, further tests showed that the first method had comparable accuracy to the second more complex method and it was recommended that the first method be used provisionally until the replacement by a new method. Nevertheless, this method is appropriate for use in specific cases, e.g., where additional information is required and for assistance in the development of improved methods.

For broadcast planning requirements it was decided to produce a relatively simple method allowing a large number of compatibility computations in a short time with existing computers at that time. The third CCIR method «Report 894» was issued in 1990 (CCIR, 1990a). The field strength model is a combination of a simplified version of the CCIR method «Report 252-2» for path lengths less than $7000 \mathrm{~km}$ and the FTZ model developed by the Deutsche Bundespost (Damboldt 1975; Damboldt and Suessmann, 1989) for path lengths greater than $9000 \mathrm{~km}$, with interpolation in the interval.

The procedure was refined in the light of experience gained in the implementation of a rapid computation method «HFBC-84» for the use of the HF Broadcast World Administrative Radio Conference (ITU, 1984) and of extensive testing within ITU-R Study Group 3. The current ITU-R procedure is now «Recommendation ITU-R P.533» (ITU-R, 1995b). Antenna gain is calculated at both the transmitter and the receiver for ten different types of antenna according to Recommendation ITU-R BS.705 (ITU-R, 1995c). The procedure has been expanded to include the estimation of signal-to-noise ratio, LUF and circuit reliability. The standard deviation between predicted monthly median sky-wave signal intensities and values derived from measurements in the ITU-R agreed data bank has improved from about $15 \mathrm{~dB}$ to about $10 \mathrm{~dB}$. The computer implementation of this method, program REC533 version 3.0 (30 October 1996), was produced together with a user's guide and made available for distribution by the ITU. This new version of the program is in accordance with the revised Recommendation. In particular, the improved modelling of ionospheric absorption and the new definition of basic circuit reliability of Recommendation ITU-R P.842 (ITU, 1994d) were incorporated. The opportunity was also taken to upgrade the program with the provision of a multi-mode output option. Figure 4 is one example of the seven available outputs of the program REC533 while fig. 5 is an example 


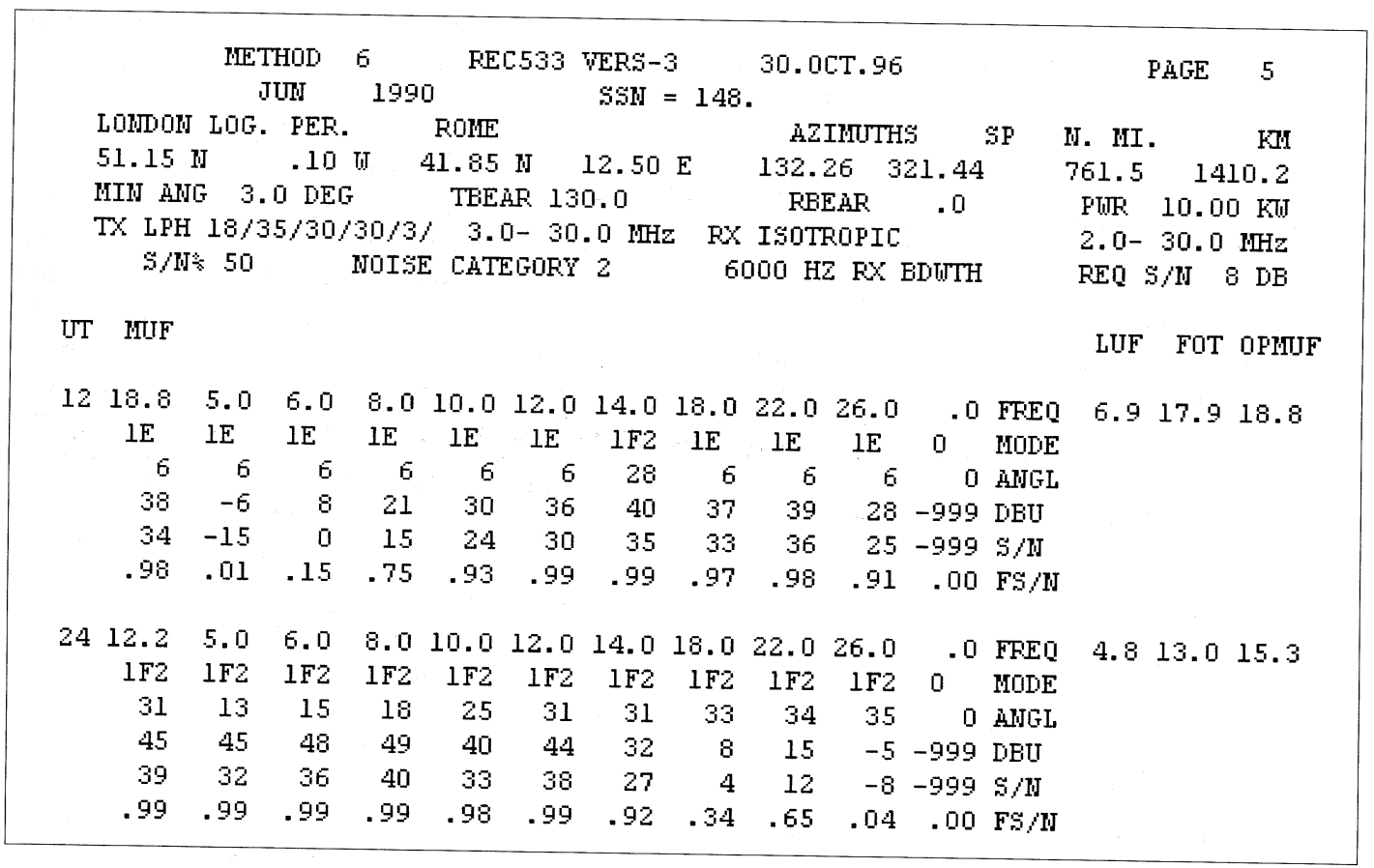

Fig. 4. Example of program REC533 method 6 output.

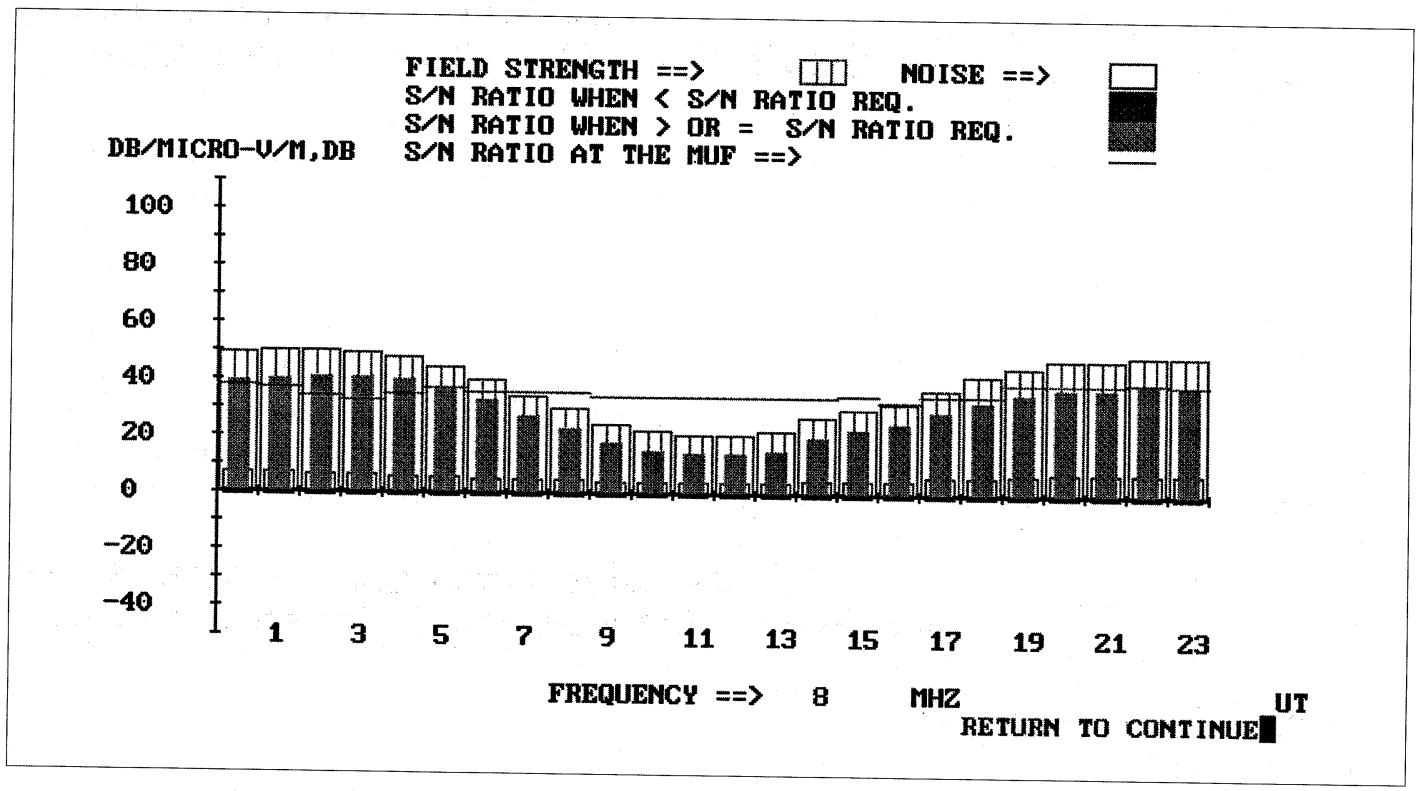

Fig. 5. Example of Program R533238 graphical presentation of field strength, noise and signal-to-noise ratio for the circuit of fig. 4 . 
of another of the seven available outputs of a «modified» program REC533 that has the same seven outputs as the standard REC533 except that $f_{0} F_{2}$ and $M(3000) F_{2}$ are generated using the PRIME map algorithms within the COST 238 area (Dick, 1998). Although designed to be relatively simple and quick to use where large numbers of path computations were to be performed, it has proven to be sufficiently accurate for the prediction of $\mathrm{HF}$ circuit performance and system design.

\subsection{Overview of performance prediction procedures}

There are many performance prediction procedures generated by different organisations. The earliest procedures provided only ionospheric reflection parameters while the later ones included systems parameters. Table III shows the more familiar of these and the suitable references. Comment on selected procedures are presented.

A long chain of methods has been generated by United States Department of Commerce at Boulder, Colorado including ITSA-1 (Lucas and Haydon, 1966), ITS-78 (Barghausen et al., 1969), HFMUFES4 (Haydon et al., 1976), IONCAP (Teters et al., 1983). ITSA-1 was presumably the first computerised procedure using a fully numerical representation of ionospheric characteristics. MUF variability, circuit and service reliability were for the first time included. IONCAP (Ionospheric Communications Analysis and Prediction Program), the latest mainframe computer program produced at Boulder, included more advanced ionospheric behaviour representation, antenna gain models and transmission loss factors. HFMUFES4 and IONCAP were widely used in many countries. These methods have influenced the development of the scheme of other prediction methods. At the same time, the United States Naval Research Laboratory has developed its own procedure «RADARC» (Thomason et al., 1979) mainly for the performance evaluation of HF radar systems. The existing procedures have been extended by SRI International (Hatfield, 1980), under sponsorship of the United States Defense
Nuclear Agency, to incorporate the following features: sporadic- $E$ modes and losses on reflection and transmission, a model of the auroral ionosphere and a model of auroral absorption that varies with magnetic activity.

A different approach was adopted in the Deutsche Bundespost by Ochs (1970), Damboldt (1975) and Damboldt and Suessmann (1989). This FTZ technique was based on a fully empirical representation of field strength generated from measurements of sky-wave signal intensities of a number of circuits with the large majority of the paths terminating in Germany.

Methods for predicting the performance of $\mathrm{HF}$ radio systems have a wide range of applications in developing countries located mostly in tropical and sub-tropical regions. Methods used were presented by Xianru and Zhenzhong (1987), Reddy et al. (1987) and Pérès (1987) in a joint Handbook that can be used as a reference document by developing countries.

One of the first microcomputer programs was MINIMUF-3 (Levine et al., 1978). At this time the main difficulty was to obtain an adequate simple and accurate microcomputerbased prediction of the world-wide variations of ionospheric characteristics. MINIMUF-3 used a simplified empirical ionospheric model for MUF predictions in a mobile environment that was originally used in the Propagation Forecast Terminal (PROPHET) of the United States Naval Ocean Systems Center. A number of improved versions have been generated, the more familiar were MINIMUF (Rose, 1982) and the latest named MINIMUF-85 (Sailors et al., 1986). MINIMUF was one of the foremost programs unrestrainedly distributed to the public and widely used by the radio amateurs community. This technique was subsequently developed by Deveureux and Wilkinson (1983) and used by Gerdes (1984) who introduced the method of predicting the ionospheric absorption described by George and Bradley (1974). An alternative way of representing the $F$-layer characteristics was given by Fricker (1985) based on a set of functions constructed to fit the ITU reference ionospheric maps and was introduced in a simplified propagation prediction method (Fricker, 1987). The approach chosen 
Table III. Example of performance prediction procedures.

\begin{tabular}{|c|c|c|}
\hline Method name & Organization & References \\
\hline Circular 462 & CRPL, CO, U.S.A. & NBS Circular 462 (1948) \\
\hline RPU-9 & $\begin{array}{l}\text { U.S. Army Signal Radio } \\
\text { Propagation Agency, NJ, U.S.A. }\end{array}$ & Laitinen and Haydon (1950) \\
\hline SPIM method & SPIM, France & Rawer (1952); Halley (1965) \\
\hline USSR method & Academy of Sciences, U.S.S.R. & Kasantsev (1956) \\
\hline DSIR method & Appleton Laboratory, U.K. & Piggott (1959) \\
\hline ITSA-1 & ITS, Boulder, CO, U.S.A. & Lucas and Haydon (1966) \\
\hline ITS-78 & ITS, Boulder, CO, U.S.A. & Barghausen et al. (1969) \\
\hline FTZ & Deutsche Bundespost & Ochs (1970) \\
\hline CCIR Report 252-2 & CCIR & CCIR Report 252-2 (1970) \\
\hline HFMUFES4 & ITS, Boulder, CO, U.S.A. & Haydon et al. (1976) \\
\hline MINIMUF-3 & NOSC, San Diego, CA, U.S.A. & Levine et al. (1978) \\
\hline RADARC & $\begin{array}{l}\text { ITS, Boulder, CO/NRL, } \\
\text { Washington, DC, U.S.A. }\end{array}$ & Thomason et al. (1979) \\
\hline $\begin{array}{l}\text { CCIR Supplement to } \\
\text { Report } 252-2\end{array}$ & CCIR & $\begin{array}{l}\text { CCIR Supplement to Report } \\
252-2 \text { (1980) }\end{array}$ \\
\hline $\mathrm{AMBCOM}$ & SRI International, U.S.A. & Hatfield (1980) \\
\hline MINIMUF & NOSC, San Diego, CA, U.S.A. & Rose (1982) \\
\hline IONCAP & ITS, Boulder, CO, U.S.A. & Teters et al. (1983) \\
\hline HFBC-84 & WARC/ITU & ITU (1984) \\
\hline MICROPREDIC & CRC, Ottawa, Canada & Petrie et al. (1986) \\
\hline MINIMUF-85 & NOSC, San Diego, CA, U.S.A. & Sailors et al. (1986) \\
\hline Fricker method & BBC, U.K. & Fricker (1987) \\
\hline HFRPCP86 & CNET, France & Davy et al. (1987) \\
\hline MICROP2 & RAL, U.K. & Dick and Miller (1987) \\
\hline NPL & NPL, India & Lakshmi et al. (1987) \\
\hline HFPROP & WARC/ITU & ITU (1987) \\
\hline MINIFTZ & Deutsche Bundespost & Damboldt and Suessmann (1989) \\
\hline IONOPROP & Hitney, MA, U.S.A. & Hitney (1990) \\
\hline CCIR Report 894 & CCIR & CCIR Report 894-2 (1990a) \\
\hline EINMUF & NRL, Washington, CA, U.S.A. & Daehler (1990) \\
\hline ASAPS & IPS, Australia & IPS (1991) \\
\hline SPARC & Institute for Applied Geophysics, U.S.S.R. & Teryokhin et al. (1992) \\
\hline $\begin{array}{l}\text { ITU-R } \\
\text { Recommendation } 533\end{array}$ & ITU-R & $\begin{array}{l}\text { ITU-R Recommendation P.533 } \\
\text { (1995b) }\end{array}$ \\
\hline
\end{tabular}


by Hortenbach and Scholz (1982) was to store the $F$-layer characteristics depending on the user's needs. Alternatively, the use of grid storage of tabular values with spatial and temporal interpolation has been adopted (Turner, 1985; Damboldt and Sussmann, 1989). However for world-wide applications the numerical coefficient approach is more efficient than the grid-point procedure. The propagation prediction method proposed by the CCIR to the HF Broadcast World Administrative Radio Conference was adapted for microcomputers by Pan and Ji (1985) and Petrie et al. (1986). Furthermore, in the last reference, computation of noise and reception reliability were added.

As microcomputer storage capacities and computing speeds increased, all these simplifications of mainframe methods disappeared. The «IPS Advanced Stand Alone Prediction System» (ASAPS) developed by the Ionospheric Prediction of Australia (IPS, 1991) was widely adopted in many countries. This program uses the Australian T-index (see section 2.1). The former U.S.S.R. System of Prediction and Analysis of Radio Communication (SPARC) was designed for long- and short-term HF ionospheric system performance prediction (Teryokhin, 1992). Many methods have been developed based on the MINIMUF, IONCAP and IUT approach. It is now possible to count in tens the Internet proposals of programs. The ITU-R propagation prediction program (ITU-R, 1995b) can be obtained from the ITU.

\section{Short-term prediction and operational considerations}

Long-term propagation predictions are issued for representative ionospheric environments. Such predictions provide information for example on the operational range of frequencies and working conditions (such as antenna types, transmitter power and required signal-to-noise ratio) to have a reliable radiocommunication service $90 \%$ or 27 of the days during one month at a given hour. Nevertheless, there will be three days of the month when the radiocommunication service is predicted unusable and fails. Most of the time, these are the days of the month when the ionosphere is «disturbed». However some radiocommunication services would benefit from having, as far in advance as possible, information on the probable values of the lower and the upper frequencies limits and disturbance warnings.

The essential aim of short-term predictions is to take account of temporary ionization anomalies due to perturbations which cannot be considered for long term predictions more than a month in advance. Short-term predictions refer to the hour-to-hour, day-to-day and weekto-week variability. This variability is analyzed generally with reference to long-term predictions. The peculiar features of variability at high latitudes should be emphasized, with particular attention to the occurrence of ionospheric patches and blobs (Radicella and de Franceschi, 1996). The anomalies are either abnormally low or abnormally high ionization levels, where the latter may be accompanied by excessive absorption in the lower layers of the ionosphere. Short-term prediction techniques are therefore based on detecting and identifying as quickly as possible all solar and geomagnetic phenomena likely to precede ionospheric perturbation and evaluating the scale of such perturbations. Short-term prediction techniques involve identifying the solar and geomagnetic events, amongst those that are constantly observed, that are precursors of ionospheric disturbance. This first of all requires a rapid collection of a large quantity of data from various observatories scattered throughout the world. It is then necessary to analyse the data in order to identify and understand the geophysical phenomena as they emerge. The possible consequences for radiocommunication services can be worked out with reference to similar situations that appeared earlier.

Since 1962, through the International Ursigram and World Days Service, these data are collected from solar and ground observatories around the world, coordinated and exchanged. The information is regularly transmitted by radio at scheduled times by certain countries, transmitted by telex during more than three decades and now are distributed by using more modern exchange support from the organiza- 
tions to regional centres which in turn distribute them to users of this service. In particular, real-time solar and space environment information is now available on Internet. Material distributed can be divided into two categories:

- Results of observations of the main solar parameters (description of sunspots, summaries of survey on solar flares, intensity of coronal line emissions, measurements of radio flux from the sun at different frequencies), geomagnetic data, flux values of cosmic rays, ionospheric data (ionospheric characteristics obtained from vertical soundings, absorption observations and sudden ionospheric disturbances) and auroral observations.

- Predictions for solar and geomagnetic parameters (radio flux, $X$-ray radiation probability and magnetic activity indexes) made by specialists in these different fields, attached to the observatories.

Information on availability and exchange of basic data and radio propagation forecasts are given in ITU-R (1995d) including an outline of the services provided by organizations which currently issue short-term forecasts. Material on short-term prediction of solar-induced variations of operational parameters for ionospheric propagation is mainly to be found in CCIR (1990b) and in two independent series of publications: those of the Special Committee on Solar-Terrestrial Physics (SCOSTEP) which, in cooperation with the Committee on Space Research (COSPAR), organizes every three or four years symposia on the subject and those of the International Ursigram and World Days Service which has initiated a series of periodic workshops devoted more especially to techniques for predicting solar-terrestrial relations (Hruska et al., 1992). The greatest fractional variations in the $E$ and $F$ regions arise in $f_{0} F_{2}$. Therefore a useful improvement in modelling is to use near real-time locally measured values of $f_{0} F_{2}$ to predict short-term MUF variations. Practical schemes for short-term forecasts are described in CCIR (1990c).

In order to take full advantage of the HF communications potential of the ionosphere and to overcome its inherent variability, frequency management should be implemented in three stages, namely long-term prediction, short-term prediction and real-time channel evaluation (RTCE). According to Darnell (1978), «real-time channel evaluation is the term used to describe the processes of measuring appropriate parameters of a set of communication channels in real time and of employing the data thus obtained to describe quantitatively the states of those channels and hence the relative capabilities for passing a given class, or classes of communication traffic». RTCE is the third stage for a frequency management system required to maintain reliable high quality $\mathrm{HF}$ communications under even the most adverse conditions. It is at this stage that all available assigned frequencies, as indicated by short-term forecasts of the usable frequency band, are examined in real-time to see which is the best to use for a given communication purpose. At this stage, account is taken of interference from other users. When predictions are employed for real-time frequency management, it is usual to seek to update the long-term predictions in terms of locally measured real-time values of $f_{0} F_{2}$ or magnetic $K$-index. For following investigations, vertical-incidence, oblique-incidence or backscatter soundings and in-channel soundings can be used to improve representations of the effective ionospheric conditions. A summary of RTCE techniques is provided in CCIR (1990d).

\section{Future needs and improvements}

Within the last thirty years performance prediction accuracy has significantly improved with the introduction of numerical mapping methods which allow the applicability of realistic models of ionospheric propagation and the HF radio systems performance programs have been extensively revised. However, despite the considerable progress obtained during the last decade, there remain studies that should be pursued further in order to improve and to develop the techniques.

The fundamental limitation to further improvements appears now to be the lack of better statistical variability knowledge of the ionospheric and noise parameters and their interrelations. Further studies should include for example modelling of sporadic- $E$, spread- $F$, irreg- 
ularities and transient phenomena and the vertical distribution of electron density. In particular, efforts should also be pursued towards the development of hour-to-hour and day-to-day variability modelling and prediction capabilities, especially for the sporadic- $E$ layer. Another example of further requested improvement is the production of methods for calculating the reliability and compatibility of HF radio systems. Furthermore, a more complete description of the ionosphere is desirable with the development of systems using digital modulation techniques and the introduction of operational over-the-horizon HF backscatter radars for frequency management and surveillance.

Requirements for prediction and forecasting methods improved over those currently available internationally are identified in this section. The parameters that should be taken into account are indicated. A variety of procedures that should be developed are examined for improvement of performance prediction.

\subsection{Models}

\subsubsection{Ionospheric characteristics}

The sources of error in ionospheric modelling primarily include the following:

- The insufficiency of data in a particular geographic area.

- The smoothing of basic data intrinsic to the mathematical representation.

- The unstable and changeable relations between the ionospheric characteristics and the solar activity index both in the rising and descending phase of the solar cycle and from cycle to cycle.

Data banks of digitized measurements of the standard ionospheric characteristics for all levels of solar activity for 3-4 solar cycles are now readily accessible. It is hoped that future improvements in the representation of $F_{2}$ peak density and peak height, including the question of long-term trends of ionospheric change which has not yet been answered, can be obtained with this larger ionosonde data base and also by applying more sophisticated numerical analysis procedures. Particular attention should be given to improvements in the representation of the ionospheric characteristics over ocean regions, at high latitudes and in the tropical zone. The potentiality of representation of the auroral oval for distinct levels of magnetic activity also merits attention. Through lack of an available model, the prediction procedures currently used assume a constant value of peak height for the $E$-layer: introduction in the future of a diurnal variation may be possible.

Studies towards the new COST 251 monthly median mapping procedures are as follows:

- Modification of monthly median ionospheric parameters given by existing COST 251 models extended in area by the use of formulations that characterize specific features of the high latitude ionosphere such as auroral oval, the $F_{2}$ region ionization trough, the ionization due to auroral $E$ layer formation, auroral absorption and electron-density irregularities in the $E$ and $F$ regions.

- Development of a regional ionospheric model by expanding ionospheric data available in the COST 251 data bank into spherical harmonics allowing for the longitudinal variation and the best correlation function between ionospheric and solar-geomagnetic parameters.

- Consideration of neural network models as an alternative to classical models of time series prediction (Lamming, 1997).

In order to achieve these targets, improvement in the world-wide ionospheric observing programme for numerical mapping purposes may be of benefit, in particular by improving the availability of the data from the existing network of ionosondes and expanding the existing network for regions where the data are limited.

\subsubsection{Electron-density height profile}

An improved model of the vertical height distribution of electron concentration in the $D$, $E$ and $F$ regions may be needed using the most extensive ionospheric database derived from the world network of ionosondes and other available ionospheric and solar-geophysical parameters as necessary including ionospheric observations from satellites. 


\subsubsection{Transmission loss and gain factors}

There are five areas of expected improvements that should be incorporated into revision of the methods of evaluation of transmission loss and gain factors.

- A better technique for taking account of auroral absorption is necessary knowing that this absorption is much more correlated with magnetic activity than it is with solar activity.

- The effects of sporadic- $E$ in the $F$ region oblique-path signal intensities are included in a simplified way and current procedures ignore the incidence of spread- $F$. Further studies may be of interest.

- The importance of scatter propagation, whether from the ionosphere or the ground, needs more consideration.

- An improved approach to the prediction philosophy is needed to allow for the correlation between daily values of the MUF and field strength to derive loss formulae appropriate to the principal propagation mechanisms that have been identified.

- Existing relations for antenna patterns are appropriate to antennas sited over perfect ground and the effect of real earth is introduced in a simplified way. The new improved antenna models that are now becoming available should be included in revised methods. In order to be able to calculate polarization-coupling loss, antenna relations are needed which include this wave polarization.

\subsubsection{Characteristics of radio noise and interference}

A better knowledge of the characteristics of natural and man-made radio noise from local and distant source noise and interference parameters, including the directions of arrival and the relation to changes with geophysical condition, such as solar activity, will contribute greatly to the improvement of system performance. Evaluation of the noise and interference parameters should be addressed in considering various modulation methods for system design.
Because the current models are based on old and scattered data, it is desirable to carry out noise and interference measurements and to produce a statistical description of spectrum occupancy.

\subsubsection{Propagation model}

It is desirable to improve the current methods for the estimation of oblique ray paths and determination of MUF using the best available model and to investigate whether this objective can be most effectively achieved using derived algorithms for mirror height and MUF or by directly ray-tracing through the model. This should include the estimation of the elevation angle of launch and arrival for the path since these angles determine the choice of the most suitable transmitting and receiving antennas on which circuit reliability depends. When considering the MUF, it is imperative to introduce also horizontal gradients in the $E$ and $F$ regions in opposition to accessible methods.

Specific attention should be paid to $E$-layer screening on paths beyond $2000 \mathrm{~km}$ and to mixed modes involving successive reflections from more than one ionospheric layer and to path length beyond about $10000 \mathrm{~km}$, especially for propagation off the great circle.

\subsubsection{Reliability}

Verification of the accuracy of current methods used in reliability calculations is fundamental. In particular, improved methods may be needed for estimating the circuit reliability of a path for which several propagation modes exist which takes account of the separate availability of the different modes.

The extension of the present methods of evaluation for the various types of reliability to include the effects of dispersion is essential. Information on description of the channel transfer function in appropriate statistical or simplified form may of mayor interest.

Finally, improvements in the frequency range 1.6 to $3 \mathrm{MHz}$ are necessary particularly for long-distance paths. 


\subsubsection{Hour-to-hour and day-to-day variations}

The inadequacy of current procedures for taking account of the statistical variations of ionospheric parameters is obvious. Predictions of standard vertical-incidence ionospheric characteristics which are exceeded for specific percentages of the time, e.g. $90 \%$ and $10 \%$, are based on large simplified assumptions. There are no satisfactory methods currently available for the prediction of ionospheric variability incorporating statistical description of sporadic $E$-layer characteristics and travelling ionospheric disturbances. It should be noted that the available information on sporadic $E$ is insufficient to provide statistical data of the type needed by telecommunication engineers, especially for circuits at high latitudes. Further consideration ought to be given to the loss statistics to include the effects of the sporadic- $E$ layer and above-the-MUF propagation mechanisms. In order to achieve this, the availability of hourly, daily and 5-min interval values is required.

\subsubsection{HF performance prediction at high latitude}

The behaviour of the ionosphere at high latitudes differs from that at lower latitudes principally because it is exposed to the influence of disturbances in interplanetary space and in the magnetosphere. Irregularities and transient phenomena, rapid ionospheric changes, fading, time and frequency spread of signals, large horizontal gradients and greater path loss for multi-hop modes over the ice-caps than multi-hop paths elsewhere have a disastrous influence on HF communication at high latitude. Major progress has been made in the development of refined models for the high latitude region. However HF performance prediction in the irregular high latitude ionosphere requires a particular operational model of the spatial and temporal distribution of electron density which is now unavailable. The specific propagation predictions at high latitude may be very sensitive to the dynamic changes in structures.

\subsection{Prediction procedures}

The past decade has seen an increased sophistication in HF radio systems prediction procedures for system design, planning optimum spectrum utilization and frequency management. Nevertheless, the current methods do not fully meet user requirements.

- The available prediction methods are intended primarily for use for narrow-band or analogue systems and are not adequate for the prediction of the performance of digital systems.

- There are no suitable procedures, especially for systems using digital modulation techniques, for prediction of multipath time spreading, «multipath reduction factor» (factor of the MUF for which the range of multipath propagation is less than a specified value), «Doppler reduction factor» (fraction of the MUF below which one must operate in order to remain below a certain specified Doppler spread), dependence of delay time on frequency relative to the MUF and path length and Multipath probability.

The main matters to be addressed are:

- Prediction of the variations of the characteristics of received signal with frequency, time, location, polarization and the characteristics of the antennas in use for digital modulation techniques.

- Description of the channel transfer function in appropriate statistical or simplified form.

- Information on time delay, time and frequency spreads and shifts (multipath and Doppler).

- Information may be also of interest on amplitude distribution, rapidity of variations, differential fading with antennas diversity and frequency diversity, phase and reflection and scattering by irregularities.

Current work within the ITU-R includes the following:

- To derive a representative model ionosphere suitable for both analytical and numeric ray tracing and to undertake tests using this model.

- To deduce algorithms for both $F_{1}$ and $F_{2}$ region mirror height and MUF. 
- To produce modified versions of the Recommendation ITU-R P.533 computer program and to carry out prediction-measurement comparisons using the latest appropriate data bank.

- To describe the channel transfer function in appropriate statistical or simplified form.

- To extend the present methods of evaluation for the various types of reliability to include the effects of dispersion.

- To seek to derive loss formulae appropriate to the principal propagation mechanisms that have been identified.

- To promote the extension of HF measurement campaigns and the development of an automated receiver.

- To collect data using measuring systems in accordance with standardised procedures.

- To produce a data bank of daily-hourly values of received signal intensities.

\subsection{Short-term forecasting and now-casting}

Accurate, quantitative short-term predictions of ionospheric variations a few hours and days in advance would allow more satisfactory utilization of radio frequencies and enlarge the reliability of HF radio systems.

Information is needed in particular on the following operational parameters:

- Hour-to-hour and day-to-day ionospheric variations which may be local in influence.

- Widespread disturbances associated with major geophysical or solar events.

- Amplitude and duration of ionospheric storms and their occurrence with time, location and solar activity.

- Attenuation, atmospheric noise, fading, multipath interference, group path delay and scattering.

Improvement in the world-wide ionospheric observing program for short-term and nowcasting purposes may be of interest, including the availability of the data from the existing network of ionosondes which are not always accessible, the expansion of the existing network and the collection of additional quantities and types of ionospheric information.

As an alternative to classical empirical prediction methods, the neural network approach should be helpful.

\section{Conclusions}

The principal performance prediction methods of HF radio systems have been reviewed. An important effort have been made in the general area of modelling and a number of very useful techniques were developed. Long-term predictions are required for radio system design and testing and for military and broadcast planning for some duration. Short-term predictions are specially relevant for the optimum use of the HF spectrum. There are a number of deficiencies in current procedures and most of them have been discussed. Developments which appear beneficial to consider further have been noted. Hopefully, research effort will continue to improve techniques using the developing science being gained in the upper atmosphere physics community interested in the dynamics of both the neutral and ionised atmospheres and the importance of the ionospheric and solar interactions. These studies may lead to basically different and new techniques of producing ionospheric predictions.

Finally, it should be emphasised that international co-operative research is absolutely necessary. Continuation of international co-operation in data collection will allow the development of new improved procedures. Advances in performance modelling and prediction should be achieved also by bringing together groups working in two areas, namely groups with objective radio engineering applications and groups that place more emphasis on radio science.

\section{REFERENCES}

Anderson, D.M., M. MEndillo and B. Herniter (1987): A semi-empirical low latitude ionospheric model, $R a$ dio Sci., 22, 292-306.

ANDERSON, D.M., J.M. Forbes and M. CODRESCU (1989): A fully analytical, low- and middle-latitude ionospheric model, J. Geophys. Res., 94, 1520-1524.

Barghausen, A.F., J.W. Finney, L.L Proctor and L.D. SCHULTZ (1969): Predicting long-term operational parameters of high frequency sky-wave telecommunication systems, in Environmental Science Services Administration Tech Rep. ERL 110-ITS 78, U.S. Government Printing Office, Washington, DC 20402.

BECKMANN, B. (1967): Notes on the relationship between the receiving-end field strength and the limits of the 
transmission frequency range MUF-LUF, NTZ-Comm. $J ., 6,37-47$.

Bent, R.B., S.K. Llewellyn, G. NesterczuK and P.E. SCHMID (1976): The development of a highly successful world-wide empirical ionospheric model and its use in certain aspects of space communications and world-wide total electron content investigations, in Effects of the Ionosphere an Space Systems and Communications Symposium Proceedings, edited by J. GoodMAN, Springfield, VA, U.S.A., U.S. Government Printing Office, Washington, DC 20402, vol. 13.

BILITZA, D. (1990): International Reference Ionosphere 1990, edited by D. BILITZA, NSSDC 90-22, Greenbelt, MA, U.S.A.

BILITZA, D. (1997): International Reference Ionosphere status 1995/96, Adv. Space Res., 20, 1751-1754.

Bilitza, D., K. Rawer, L. Bossy and T. Gulyaeva (1993): International Reference Ionosphere - past, present and future: electron density, Adv. Space Res., 13, 3-13.

Bossy, L. (1987): The determination of LAY-parameters for a given profile, $A d v$. Space Res., 7, 35-37.

BRADLEY, P.A. (1968): Wave polarization and its influence on the power available from a radio signal propagated through the ionosphere, Proc. IEE, 115, 771-781.

BRADLEY, P.A. (1991a): Use of ionospheric models in HF radio planning and OTH target location, in Fifth International Conference on HF Radio Systems and Techniques, IEE Conference Publication, 339, 178-182.

BRADLEY, P.A. (1991b): Use of electron density profiles in HF propagation assessment: part 1 - Requirements, prediction and forecasting; part 2 - Retrospective studies, OTH sensors and the role of the IRI, Adv. Space Res., 11, 117-126; 127-133.

BRADLEY, P.A. (1993a): Options for generating instantaneous ionospheric maps from measured data, in Proceedings of the PRIME/URSI Joint Workshop on «Data Validation of Ionospheric Models and Maps (VIM)», Roquetes, Spain, May 1992, Memoria 16, COST238TD(93)001, 300-302.

BRADLEY, P.A. (1993b): Optimum PRIME mapping, in Proceedings of the COST 238 Workshop on "PRIME Studies With Emphasis on TEC and Topside Modelling», Graz, Austria, May 1993, COST238TD (93)013, 43-49.

BRADLEY, P.A. (1996): Instantaneous ionospheric mapping, in Proceedings of the First Workshop of COST 251, Prague, Czech Republic, September 1996, COST251TD(96)017, 76-98.

BRADLEY, P.A. and J.R. DUDENEY (1973): A simple model of the vertical distribution of electron concentration in the ionosphere, J. Atmos. Terr. Phys., 35, 2131-2146.

BRADLEY, P.A., M.I. DICK, T. SMARDJIEV and S. STANKOS (1995): KIMS - a new method of instantaneous mapping using screen-point values in remote areas, in Proceedings of the COST 238/PRIME Workshop on «Development and Testing of an Electron-Density Height Profile for PRIME», El Arenosillo, September 1994, COST 238TD (95) 023, 133-136.

CANDER, Lj.R., B. Zolesi and P.A. Bradley (1996): Status of available $N(h)$ model profiles, Ann. Geofis., 39 (4), 729-733.
CCIR (1970): CCIR interim method for estimating sky-wave field strength and transmission loss at frequencies between the approximate limits of 2 and 30 MHz, Report 252-2, Inte rnational Telecommunication Union, Geneva.

CCIR (1980): Second CCIR computer-based interim method for estimating sky-wave field strength and transmission loss at frequencies between 2 and 30 $\mathrm{MHz}$, Supplement to Report 252-2, International Telecommunication Union, Geneva.

CCIR (1990a): HF propagation prediction method, Report 894-2, International Telecommunication Union, Geneva.

CCIR (1990b): Short-term prediction of solar-induced variations of operational parameters for ionospheric propagation, Report 727-3, International Telecommunication Union, Geneva.

CCIR (1990c): Short-term forecasting of critical frequencies, operational maximum usable frequencies and total electron content, Report 888-2, International Telecommunication Union, Geneva.

CCIR (1990d) : Real-time channel evaluation of HF ionospheric radio circuits, Report 889-2, International Telecommunication Union, Geneva.

Chernishyev, O.V. (1968): $f_{0} E_{\mathrm{s}}$ distribution curves, Geomagn. Aeron., 8, 902-903.

CHIU, Y.T. (1975): An improved phenomenological model of ionospheric density, J. Atmos. Terr. Phys., 37, 1563-1570.

COST (1995): COST Action 238 Final Report, Advance Issue, October 1995, Commission of the European Communities, Brussels.

DAEHLER, M. (1990): EINMUF: An HF, MUF, FOT, LUF Prediction Program, NRL Memorandum Rep. 6645, Naval Research Laboratory, Washington DC, U.S.A.

DAMBolDT, T. (1975): A comparison between the Deutsche Bundespost Ionospheric HF radiopropagation predictions and measured field strength, AGARD Conference Proceedings 173, 12.

DAMBOLDT, T. and P. SUESSMANN (1989): The FTZ HF propagation model for use on small computers and its accuracy, AGARD Conference Proceedings 453, 51.

DANIELL, R.E., W.G. WHARTENBY and L.D. BROWN (1993): Parameterised Real Time Ionospheric Specification Model, PRISM version 1.2, Validation Report, Computational Physics Inc., Newton, MA, U.S.A.

DARNELL, M. (1978): Channel evaluation techniques for dispersive communications paths, Communications Systems and Random Process Theory, edited by J.K. SKWIRZYNSKI (Sijthoff and Noordhoff, The Nederlands), 425-460.

DAVIES, R.M. (1972): The occurrence of spread-F and its effect on HF propagation, Office of Telecommunications, TRER 28, U.S. Government Printing Office, Washington, DC 20402.

Davy, P., R. HANBABA, M. Lissillour and H. SizUN (1987): Microcomputer based methods for estimation of $\mathrm{HF}$ radiopropagation and circuit performance, IEE Conference on Antenna and Propagation, IEE Conference Publication, 274, Part 2: Propagation, 297-301.

DE FRANCESCHI, G. and A. DE SANTI (1995): IMASHA technique for instantaneous ionospheric regional map- 
ping, in Proceedings of the COST 238/PRIME Workshop on "Development and Testing of an Electron-Density Height Profile for PRIME», El Arenosillo, Spain, September 1994, COST238TD(95) 023, 109-113.

DeveureuX, E.L. and D. WILKInson (1983): HF predictions on the home computer, Radio Comm., 3 , 246-248.

DICK, M.I. (1998): Rutherford Appleton Laboratory (private communication).

DICK, M.I. and B.H. MILLER (1987): Microcomputer-based method for the estimation of HF radio-circuit performance, IEE Conference on Antenna and Propagation, IEE Conference Publication, 274, Part 2: Propagation, 306-309.

DiCK, M.I. and P.A. BRADLEY (1992): The RAL multi-quasiparabolic model ionosphere, in Proceedings of the PRIME/URSI Joint Workshop on «Data Validation of Ionospheric Models and Maps (VIM)», Roquetes, Spain, May 1992, Memoria 16, COST 238TD(93)001, 67-83.

Ducharme, E.D., L.E. Petrie and R. Eyfrig (1973): A method for predicting the $F_{1}$ layer critical frequency based on the Zurich smoothed sunspot number, Radio Sci., 8, 837-839.

DUDENEY, J.R. (1978): An improved model of the variation of the electron concentration with height in the ionosphere, J. Atmos. Terr. Phys., 40, 95-203.

FOPPIANO, A.J. (1985): Morphology of background auroral absorption, J. Atmos. Terr. Phys., 47, 663-674.

Fox, M.W. and L.F. MC NAMARA (1988): Improved world-wide maps of monthly median $f_{0} F_{2}, J$. Atmos. Terr. Phys., 50, 1077-1086.

FRICKER, R. (1985): A microcomputer program for the critical frequency and height of the $F$ layer of the ionosphere, IEE Conference on Antenna and Propagation, IEE Conference Publication, 248, 546-550.

FRICKER, R. (1987): A microcomputer program for $\mathrm{HF}$ field strength prediction, IEE Conference on Antenna and Propagation, IEE Conference Publication, 274, Part 2: Propagation, 293-296.

GEORGE, P.L. and P.A. BRADLEY (1974): A new method of predicting the ionospheric absorption of high frequency waves at oblique incidence, Telecom. J., 41, 307-312.

GERDES, N. (1984): A low-cost prediction service for mobile and portable radio using ionospheric propagation, IEE Conference on Antenna and Propagation, IEE Conference Publication, 238, 209-211.

GIRALDEZ, A.E. (1980): Daytime sporadic-E blanketing frequency prediction, in International Solar Terrestrial Predictions Workshop Proceedings, Boulder, CO, C 87-C 106, U.S. Government Printing Office, Washington, DC 20402, vol. IV.

Hagn, G.H., A.J. GiBson and P.A. BradLey (1994): Propagation on frequencies above the basic MUF, in Proceedings of the 7th International Ionospheric Effects Symposium, Alexandria, VA, U.S.A., May 1993, 5A-1.

Halley, P. (1965): Méthode de calcul des prévisions de point à point aux distances comprises entre 2500 et $10500 \mathrm{~km}$, Centre National d'Etudes des Télécommunications, Division des Prévisions Ionosphériques,
Rapport Technique DPI/1065, France.

HARNISCHMACHER, E.A. (1960): A calculation method of ionospheric propagation conditions for very high and antipode distance, in Electromagnetic Wave Propagation (Academic Press, London, United Kingdom), pp. 527.

HATFIELD, V.E. (1980): HF communications predictions 1978 (an economical up-to-date computer code, AMBCOM), in International Solar Terrestrial Predictions Workshop Proceedings, Boulder, CO, D2 1-D2 15, U.S. Government Printing Office, Washington, DC 20402, vol. IV.

Haydon, G.W., M. LefTIN and R. Rosich (1976): Predicting the performance of high frequency skywave telecommunication systems - The use of the HFMUFES4 program, Office of Telecommunications, U.S. Government Printing Office, Washington, DC 20402, Rep. 76-102.

HITNEY, H.V. (1990): IONOPROP: an Ionospheric Propagation Assessment Program, published by Artech House, Norwood, MA 02062, U.S.A.

HORTENBACH, J. and H. SCHOLZ (1982): Berechnung der Raumwellenfeldstärke höchsten übertragbaen Frequenzim HF-Bereich mit Hilfe eines programmierbaren Taschenrechners, Rundfunktechn. Mitt., 26, 52-62.

Hruska, J., M.A. Shea, D.F. SMART and G. HeCKMAN (1992): Solar Terrestrial-Predictions, in Solar Terrestrial-Predictions Workshop Proceedings, Ottawa, Canada, U.S. Government Printing Office, Washington, DC 20402, vol. 1, 2 and 3.

HuANG, X. and B. REINISCH (1996): Vertical electron density profiles from digisonde ionograms. The average representative profile, Ann. Geofis., 39 (4), 751-756.

IPS (1991): ASAPS: IPS Advanced Stand Alone Prediction System, IPS Radio and Space Services, West Chatswood, NSW 2057, Australia.

IPSD (1968): The development of the ionospheric index $T$, Report IPS-RII, IPS Radio and Space Services, West Chatswood, NSW 2057, Australia.

ITU (1984): World Administrative Radio Conference for the planning of the HF bands allocated to the broadcast service, First Session, Report to the Second Session of the Conference, International Telecommunication Union, Geneva.

ITU (1987): World Administrative Radio Conference for the planning of the HF bands allocated to the broadcast service, Final Acts, International Telecommunication Union, Geneva.

ITU-BR (1997): Catalogue of software for spectrum management, International Telecommunication Union, Geneva.

ITU-R (1994a): Signal-to-interference protection ratios for various classes of emission in the fixed service below about $30 \mathrm{MHz}$, Recommendation ITU-R F.240, International Telecommunication Union, Geneva.

ITU-R (1994b): Bandwidths, signal-to-noise ratios and fading allowances in complete systems, Recommendation ITU-R F.339, International Telecommunication Union, Geneva.

ITU-R (1994c): Radio noise, Recommendation ITU-R PI.372, International Telecommunication Union, Geneva.

ITU-R (1994d): Computation of reliability and compatibility 
of HF radio systems, Recommendation ITU-R PI.842, International Telecommunication Union, Geneva.

ITU-R (1995a): Choice of indices for long-term ionospheric prediction, Recommendation ITU-R P.371, International Telecommunication Union, Geneva.

ITU-R (1995b): HF propagation prediction method, Recommendation ITU-R P.533, International Telecommunication Union, Geneva.

ITU-R (1995c): HF transmitting and receiving antennas characteristics and diagrams, Recommendation ITU- $R$ BS.705-1, International Telecommunication Union, Geneva.

ITU-R (1995d): Exchange of information for short-term forecasts and transmission of ionospheric disturbance warnings, Recommendation ITU-R P.313, International Telecommunication Union, Geneva.

ITU-R (1997a): ITU-R reference ionospheric characteristics and methods for basic MUF, operational MUF and ray-paths predictions, Recommendation ITU-R P.1239, International Telecommunication Union, Geneva.

ITU-R (1997b): Propagation on frequencies above the basic MUF, Report 2011, International Telecommunication Union, Geneva.

ITU-R (1997c): Radio-frequency protection ratios in LF, $\mathrm{MF}$, and $\mathrm{HF}$ broadcasting, Recommendation ITU-R B.560, International Telecommunication Union, Geneva.

ITU-R (1997d): ITU-R methods of basic MUF, operational MUF and ray-path prediction, Recommendation ITU-R P.1240, International Telecommunication Union, Geneva.

JIAO, P.N. and J. WU (1996): Ionospheric models and data for the Chinese subcontinent, Adv. Space Res., 18, 191-200.

JONES, W.B. and R.M. GALLET (1965): The representation of diurnal and geographic data by numerical methods, Telecom. J., 32,18-28.

JoNES, W.B. and D.L. OBITTS (1970): Global representation of annual and solar cycle variation of $f_{0} F_{2}$ monthly median 1954-1958, Office of Telecommunications ITS Research Rep. 3, U.S. Government Printing Office, Washington, DC 20402.

Jones, W.B, R.P. GRAHAM and M. LEFTIN (1969): Advances in ionospheric mapping by numerical methods, Environmental Science Services Administration Rep. ERL 107-ITS 75, U.S. Government Printing Office, Washington, DC 20402.

KASANTSEV, A.N. (1956): Developing a method of calculating the electrical field strength of short radio waves, Transactions of the Institute of Radio Engineering and Electronics of the Academy of Sciences, U.S.S.R., $2,134$.

KING, J.W. and A.J. SLATER (1973): Errors in predicted values of $f_{0} F_{2}$ and $h m F_{2}$ with the observed day-to-day variability, Telecom. J., 40, 766-770.

LAITINEN, P.O. and G.W. HAYDON (1950): Analysis and prediction of sky-wave field strength intensities in the high frequency band, U.S. Army Signal Radio Propagation Agency, Ft. Monmouth, NJ, Tech. Rep. 9.

LAMMING, X. (1997): Modélisation par réseau neuronique des fréquences critiques de l'ionosphère, in Proceedings of the 3èmes journées d'études Propagation électromagnétique dans l'atmosphère du décamétrique à l'angström, edited by Société des Electriciens et des Electroniciens, Paris, France, 215-219.

LAKSHMI, D.R., B.M. REDDY, S. SHASTRI and A.B. GHOSH (1987): Computerized HF link predictions at NPL, India, IEE Conference on Antenna and Propagation, IEE Conference Publication, 274, Part 2: Propagation, 302-305.

LEFTIN, M. and S.M. OsTRow (1969): Numerical maps of $f_{b} E_{s}$ for solar cycle minimum, Environmental Science Services Administration Tech. Rep. ERL 124-ITS 87, U.S. Government Printing Office, Washington, DC 20402

Leftin, M., S.M. Ostrow and C. Preston (1968): Numerical maps of $f_{0} E_{\mathrm{s}}$ for solar cycle minimum and maximum, Environmental Science Services Administration Tech. Rep. ERL 73-ITS 63, U.S. Government Printing Office, Washington, DC 20402.

Leftin, M., S.M. Ostrow and C. PRESTON (1969): Numerical maps of monthly median $h^{\prime} F, F_{2}$ for solar cycle minimum and maximum, Environmental Science Services Administration Tech. Memo. IERM-ITSA 69, U.S. Dep. of Commerce, Boulder, CO.

LEVINE, P.H., R.B. Rose and J.N. MARTIN (1978): MINIMUF-3: a simplified MUF-Prediction Algorithm IEE Conference on Antenna and Propagation IEE, Conference Publication, 178, 161-167.

LuCAS, D.L. and G.W. HAYDON (1966): Predicting statistical performance index for high frequency ionospheric telecommunication systems, Environmental Science Services Administration Tech Rep. IER 1-ITSA 1, U.S. Government Printing Office, Washington, DC 20402.

MikHaIlov, A.V. and V.V. MikHailov (1995): A new ionospheric index $M F_{2}, A d v$. Space Res., 15, 93-98.

MikHaIlov, A.V., V.V. MikHAILOV and M.G. SKoblin (1995): A method for $f_{0} F_{2}$ and $M(3000) F_{2}$ instantaneous mapping over Europe ( $M Q M F_{2}$-INST model), in Proceedings of the COST 238/PRIME Workshop on «Development and Testing of an Electron-Density Height Profile for PRIME», El Arenosillo, Spain, September 1994, COST238TD(95)023, 115-121.

MikhaIlov, A.V., V.V. MikhaIlov and M.G. Skoblin (1996): Monthly median $f_{0} F_{2}$ and $M(3000) F_{2}$ ionospheric model over Europe, Ann. Geofis., 39 (4), 791-805.

MIYA, K. and S. KANAYA (1955): Radio propagation prediction considering scattering wave on the earth's surface, Rep. Ion. Res., Japan, 9, 1-15.

MiYA, K., K. SChIMIZU and T. KoJIMA (1978): Obliqueincidence sporadic- $E$ propagation and its ionospheric attenuation, Radio Sci., 13, 559-570.

MugGleton, L.M. (1975): A method of predicting $f_{0} E$ at any time and place, Telecom. J., 42, 413-418.

NBS (1948): Ionospheric Radio Propagation, National Bureau of Standards, Circular 462, U.S. Government Printing Office, Washington, DC 20402.

OcHS, A. (1970): The Forecasting System of the Fernmeldetechnischen Zentralamt (FTZ), AGARD Conference Proceedings 49, 43, edited by V. AGY, Environmental Science Services Administration, U.S. Dep. of Commerce, Boulder, CO.

PAN, Z. and P. Ji. (1985): HF field strength measurements in China and their comparisons with predicted values, 
CCIR IWP/6.1, Doc. L7, International Telecommunication Union, Geneva.

PÉRÈS, M. (1987): Method used in Argentina for HF communications, in Handbook on Radio Propagation for Tropical and Subtropical countries, edited by A.P. MitRA, B.M. REDDY, S.M. RADICELLA, J.O. OYINLOYE and S. FENG (URSI), 239-245.

Petrie, L.E., G.W. Goudrie, D.B. Ross, P.L. Timleck and S.M. CHOW (1986): MICROPREDIC - An HF Prediction Program for 8086/8088-based computers, Communications Research Centre Rep. 1390, Ottawa, Canada.

PIGgotT, W.R. (1959): The calculation of the median sky-wave field strength in the tropical regions, DSIR Radio Research Special Rep. 27, HMSO, London, U.K.

RADICELla, S.M. (1995): IRI Task Force, in Proceedings of the IRI Task Force Activity '95 on F, Layer and the Shape of the $\mathrm{Ne}$ profile below $\mathrm{NmF}_{2}$, UNESCO and IAEA, ITCP, Trieste, Italy.

RADICELLA, S.M. (1996): Forecast and ionospheric variability with particular reference to high latitudes, in Proceedings of the First Workshop of COST 251, Prague, Czech Republic, September 1996, COST251 TD(96)017, 69-75.

RADICELLA, S.M. and M.L. ZHANG (1995): The improved DGR analytical model of electron density height profile and total electron content in the ionosphere, Ann. di Geofis., 38 (1), 35-41.

RADiCELlA, S.M. and G. DE FrANCESCHI (1996): Forecast and ionospheric variability with particular reference to high latitude, in Proceedings of the First Workshop of COST 251, Prague, Czech Republic, September 1996, COST251TD(96) 017, 76-98.

RAO, M.K. (1952): Nomographs for calculation of field strength, J. Inst. Telecomm. Engineers, India, 15, $729-740$

RAWER, K. (1952): Calculation of sky-wave field strength, Wireless Engineer, 29, 287-301.

REDDY, B.M, D.R. LAKShMI, S. AgGaRWAL and S. SHASTRI (1987): Method used in India: HF System Predictions, in Handbook on Radio Propagation for Tropical and Subtropical Countries, edited by A.P. MITRA, B.M. REDDY, S.M. RADICELlA, J.O. OYINLOYE and S. FENG (URSI), 185-206.

Rose, R.B. (1982): «MINIMUF»: a simplified MUFprediction program for microcomputers, $Q S T$, vol. 66 , 12, 36-38.

Rush, C.M., D. MilleR and J. GiBbs (1974): The relative daily variability of $f_{0} F_{2}$ and $h m F_{2}$ and their implications for HF radio propagation, Radio Sci., 9, 749-756.

Rush, C.M., M. PoKemPNer, D.N. ANDERson, J. PERry, F.G. STEWARD and R. REASONER (1984): Maps of $f_{0} F_{2}$ derived from observations and theoretical data, Radio Sci., 19, 1083-1097.

Rush, C.M., M. Fox, D. Bilitza, K. Davies, L. MC NAMARA, F.G. STEWARD and M. POKEMPNER (1989): Ionospheric mapping: an update of $f_{0} F_{2}$ coefficients, Telecom. J., 56, 179-182.

SAILORS, D., R.A. SPRAgUe and W.H. RIX (1986): MINIMUF-85: an Improved HF MUF Prediction Algorithm, NOSC TR 1121, Naval Ocean Systems Cen- ter, San Diego, CA, U.S.A.

SAmardjIEV, T., P.A. Bradley, Lj.R. CANDER and M.I. DICK (1993): Application of computer contouring to instantaneous mapping, in Proceedings of the COST 238 Workshop on "PRIME Studies with Emphasis on TEC and Topside Modelling», Graz, Austria, May 1993, COST238TD(93)013, 257-269.

Scotto, C., M. Mosert De Gonzalez, S.M. Radicella and B. ZOLESI (1997): On the prediction of $F_{1}$ ledge occurrence and critical frequency, Adv. Space Res., 20, 1773-1775.

SECAN, J.A. and P.J. WILKINSON (1997): Statistical studies of an effective sunspot number, Radio Sci., 32, 1717-1724.

SinNO, K., M. KAN and Y. HiRUKAWA (1976): On the reflection and transmission losses for ionospheric radio wave propagation via sporadic E, J. Radio Res. Labs, Japan, 23, 65-84.

SMITH, E.K. (1976): World maps of sporadic-E $\left(f_{0} E_{\mathrm{s}}>7\right.$ $\mathrm{MHz}$ ) for use in prediction of VHF oblique-incidence propagation, Office of Telecommunication Spec. Publ. 76-10, US Dep. of Commerce, PB 255904, NTIS, Springfield, VA.

SMiтH, E.K. (1978): Temperate zone sporadic- $E$ maps $\left(f_{0} E_{\mathrm{s}}>7 \mathrm{MHz}\right)$, Radio Sci., 3, 571-575.

SINGER, W. and N.I. DVINSKIKH (1991): Comparison of empirical models of ionospheric characteristics developed by means of different mapping methods, $A d v$. Space Res., 11, 3-6.

STANILAWSKA, I. and G. JUCHNIKOWSKI (1997): A note on use of screen points in regional ionospheric mapping, Acta Geophysica Polonica, 45, 355-362.

STANILAWSKA, I., G. JUCHNIKOWSKI and LJ.R. CANDER (1996): The Kriging method of ionospheric parameter $f_{0} F_{2}$ instantaneous mapping, Ann. Geofis., 39 (4), 845-852.

TAscione, T.F., H.W. Kroehl, R. Creiger, J.W. Freeman, R.A. Wolf, R.W. SpIro, R.V. Hilmer, J.W. SHADE and B.A. HAUSMAN (1988): New ionospheric and magnetospheric specification models, Radio Sci., 23, 211-222.

TERYOKHIN, Y. (1992): System of Prediction and Analysis of Radio Communication, Solar Terrestrial-Predictions Workshop Proceedings, Ottawa, Canada, edited by J. Hruska, M.A. ShEA, D.F. SMART and G. HeCKMAN, U.S. Government Printing Office, Washington, DC 20402, vol. 3, 555-567.

TETERS, L.R, J.L. LlOYD, G.W. HAYdON and D.L. LuCAS (1983): Estimating the performance of telecommunication systems using the ionospheric transmission channel - Ionospheric Communications Analysis and Prediction Program User's Manual, National Telecommunication and Information Administration Rep. 83-127, Boulder, Co, U.S.A.

Thomason, J., G. SKaggs and J.A. Lloyd (1979): A global ionospheric model, Naval Res. Lab. Rep. 8321, U.S. Government Printing Office, Washington, DC 20402.

TURNER, J.F. (1985): A grid-point system for prediction data, Tech. Rep. TR-85-08, IPS Radio and Space Services, West Chatswood, NSW 2057, Australia.

XIANRU, S. and P. ZHENZHONG (1987): Method used in 
China: system calculations for HF circuits, in Handbook on Radio Propagation for Tropical and Subtropical countries, edited by A.P. MITRA, B.M. REDDY, S.M. RADICELLA, J.O. OYINLOYE and S. FENG (URSI), $159-168$

Zolesi, B. and M. Mosert De GonZalez (1995): On the application of the $\mathrm{Du}$ Charme formula for predicting the $F_{1}$ layer critical frequency, in Proceedings of the IRI Task Force Activity '95 on F1 Layer and the Shape of the $\mathrm{Ne}$ profile below $\mathrm{NmF}_{2}$, UNESCO and IAEA, ITCP, Trieste, Italy, 52-54.
Zolesi, B. and LJ.R. CANDER (1996a): Advances in regional ionospheric mapping, in Proceedings of the First Workshop of COST 251, Prague, Czech Republic, September 1996, COST251TD(96)017, 52-68.

ZOLESI, B. and LJ.R. CANDER (1996b): Interfacing between regional and global electron density height profile, Ann. Geofis., 39, 883-889.

ZOLESI, B., LJ.R. CANDER and G. DE FRANCESCHI (1996): On the potential applicability of the simplified ionospheric regional model to different mid-latitude areas, Radio Sci., 31, 547-552. 